Portland State University

PDXScholar

$1-1-2011$

\title{
The Cultural Barriers to Integration of Second Generation Muslims in Northern Italy
}

Joseph Anthony Migliore

Portland State University

Follow this and additional works at: https://pdxscholar.library.pdx.edu/open_access_etds Let us know how access to this document benefits you.

\section{Recommended Citation}

Migliore, Joseph Anthony, "The Cultural Barriers to Integration of Second Generation Muslims in Northern Italy" (2011). Dissertations and Theses. Paper 231.

https://doi.org/10.15760/etd.231

This Thesis is brought to you for free and open access. It has been accepted for inclusion in Dissertations and Theses by an authorized administrator of PDXScholar. Please contact us if we can make this document more accessible: pdxscholar@pdx.edu. 
The Cultural Barriers to Integration of Second Generation Muslims in Northern Italy

by

Joseph Anthony Migliore

A thesis submitted in partial fulfillment of the requirements for the degree of

\author{
Master of Arts \\ in \\ Conflict Resolution
}

Thesis committee:

Harry Anastasiou, Chair

Rob Gould

Aimee Clott

Portland State University

(C)2011 


\begin{abstract}
In this study, I examine the existing literature and carry out a qualitative exploration in order to formulate a better understanding of the dynamics that influence the lives of $2^{\text {nd }}$ generation Italian Muslims. Although monumental social and political challenges remain in confronting integration of the Muslim population and for achieving greater acceptance of Islam within the Italian public sphere, the evidence suggests that the process for integration has slowly begun. Additionally, this study examines the intellectual framework of the existing literature which addresses the issues impacting Muslim integration in Northern Italy. This issue has induced new debates within Italy on multiculturalism, national identity, human rights, while more importantly raising the question - "to what extent do we allow Muslim integration into Italian society and the further insertion of Islam into Italy's spiritual geography?"
\end{abstract}

This study argues that the convergence of contemporary international affairs with religion calls for a new lens for interaction. In Italy the events following 9/11, combined with a resurgence of Islamophobia and the impact of the Global War on Terror, have drawn the issue of Muslim immigrants into a negative spotlight. Mainstream attitudes in Europe, following 9/11, have generated a rift in Muslim-West relations and have caused confusion and anxiety among Muslims and non-Muslims alike. The research hypothesis for this thesis suggests that there are multiple factors impeding the efforts for Muslims to achieve equal footing within the Italian religious landscape and inclusion within Italian society. Among these are divisions found within the Muslim community itself, a 
growing mistrust of Islam in mainstream Italian society, sponsored by negative media stereotyping and xenophobic political movements, and underlying everything else, the privileged position of the Catholic Church and its unwillingness to accommodate Islamic identity within the social framework. The chosen methodology employed in this study is qualitative, theoretical contextual analysis combined with interviews plus questionnaires used to construct a case study were applied. Beyond engaging in seven interviews with the $2^{\text {nd }}$ generation Italian Muslims, this study was informed by the relevant academic literature from the fields of conflict resolution, history, sociology, cultural studies, Islamic studies and political science.

Finally this study contextualized the dynamics generating this conflict and examined the discontinuities this situation has created in the lives of Muslims in Italy. The exclusion of the Muslim population, coupled with the complex relationship between this cultural group and state, has led to the exploration within Italy of different models for integration. The findings of this study indicate that inequalities exist for the Muslim population of Northern Italy in their relation with the host nation and society. This further hampers the process of integration and generates further exclusion. Only profound rethinking of the Italian approach to integration will serve to adequately meet the needs of this marginalized population and fully incorporate them within Italian society. 


\section{DEDICATION}

This thesis is dedicated to the second generation Muslim population in Italy and to the GMI (Young Muslims in Italy). May they find greater inclusion within European society while achieving their goals in reaching a more equitable society. To the GMI, who I owe a sincere thank you for allowing my participation in your focus groups in Umbria, Italy and to the subjects in this study, which inspired me in achieving a greater understanding. This thesis is also dedicated to my three sons, Alexander, Anthony and Michael, who have been supporting my endeavor in completing this study since the beginning. Without their patience and encouragement this thesis may not have been written. May the results of this thesis help them achieve a greater understanding of Islam and lead to greater tolerance in Italian society for the future. 


\section{Acknowledgments}

There are many scholars and community representatives who I had the pleasure in meeting and who I wish to sincerely thank. I am most thankful to Professor Harry Anastasiou for guiding me through this rigorous academic journey as I found my voice and gained much needed discourse in framing cultural conflict within the Italian context. I wish to also thank Professor Paolo Branca, from the Universitá Cattolica in Milan, without his intellectual insight, guidance and personal assistance in assisting with my research design, my research would not have been possible. It was through Professor Branca's efforts that the coordinating and logistical preparations of my interviews, the meeting with community leaders all became possible. Without Prof. Branca's efforts, the research would not have been thorough. Through his acquaintances and unwavering efforts, I was able to meet and engage with Muslim community leaders, Imams' and participate in the annual GMI Muslim youth conference-held in December 2008, a conference which typically does not permit non-Muslims from attending.

A special thank-you to, Professor Davide Tacchini, of Hartford Seminary, who also provided advice and guidance with my research. Additionally, I would like to thank, Imam Dahmane Abdullah, of the Via Padova Islamic Cultural Center (Casa Della Cultura Islamic di Milano), who welcomed me to his Mosque and allowed me to participate in many discussions with the Muslim community and with the Muslim youth. I also would like to thank the following community leaders, who provided untiring efforts in meeting with me on many occasions and with assisting me in gaining a better understanding of the Muslim population while conducting my research. Additionally, Professor Stefano Allievi, leading Sociologist from Padua University and Rev. Dott. Giampiero Alberti, of CADR Milan, Abadallah Kabakebbji, of the Giovani Mulsumani di Italia (GMI), Dott. Antonio Cuciniello, of ISMU in Milan and to the U.S. Consulate in Milan, where I was given guidance and a wonderful suggestion back in 2008 while completing my internship, resulting in my meeting Professor Paolo Branca.

Lastly, I wish to thank the professionalism of the Millar Library reference desk staff, for their unwavering assistance; Michael Bowman and Allen Hauser were incredibly helpful from assisting with literature to advice on structure, without their devoted efforts, my thesis would not have been possible and a special thank-you to the following library staff; Art Hendricks, Bertrand Robinson and Sherry Buchanan, for making my literature, books and research possible. 


\title{
Table of Contents
}

\begin{abstract}
.......................................................................i

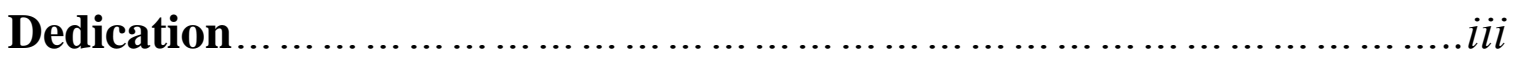

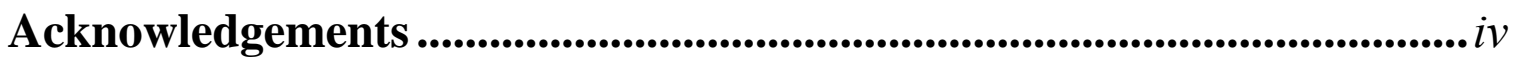

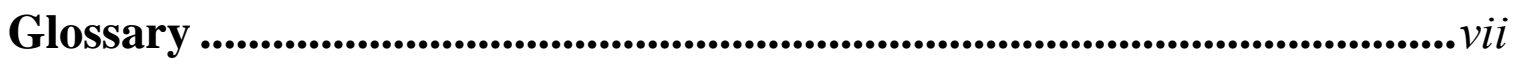

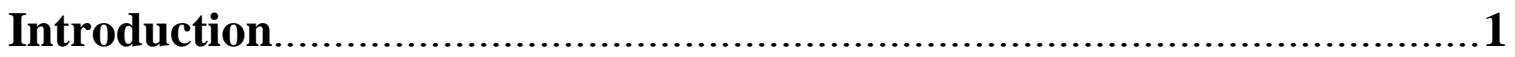

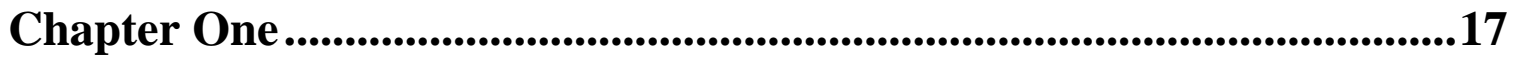

Historical Background of Islam and Its Influence

In the Western Mediterranean

Chapter Two

Literature Review

Chapter Three

Methodology

Chapter Four.

Defining Islamophobia

Chapter Five 
The Concept of Multiculturalism: A Recent Historical Background

Chapter Six.............................................................................................105

Discussion.

The Concern of Islam--Models of Integration

For Second Generation Muslims ................................................... 105

Muslims in Italy, the Role of Citizenship.................................................. 109

Factors Influencing Assimilation-The Role of Identity ..............................110

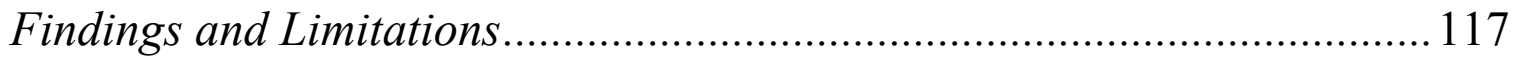

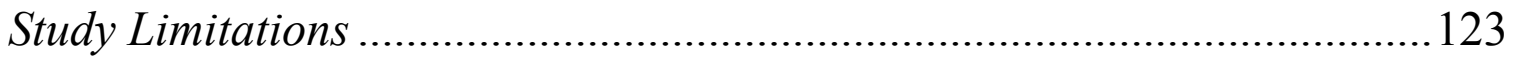

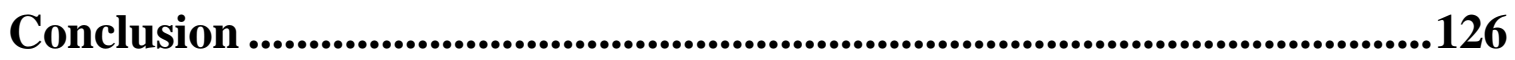

Suggestions for Further Research ........................................................129

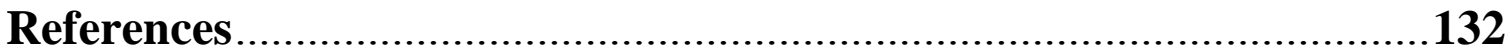

\section{Appendices:}

Appendix A - Research Questionnaire ............................................................ 135

Appendix B - Human Subjects Review Application ............................... 138

Appendix C - Human Subjects Consent Form..................................... 147 


\section{GLOSSARY}

Caliph for Sunni Muslims, successor of Muhammad as leader of the Islamic community

Dar al-Islam "abode of peace"; Islamic territory, i.e., where Islamic law is in force

Hadith narrative report of the Prophet Muhammad's sayings and actions

Hijab veil or head scarf worn by Muslim women in public

Ijtihad independent analysis or interpretation of Islamic law

Imam "Leader," prayer leader. In Shii Islam refers to successor of Prophet Muhammad, descendant of Ali, who governs as divinely inspired religiopolitical leader of Islamic community

Kafir "unbeliever" or infidel, one who is "ungrateful" and rejects the message of Islam

Mufti specialist on Islamic law competent to deliver a fatwa or legal interpretations/brief

Shahadah confession or profession of faith: "there is no god but Allah and Muhammad is His Prophet/messenger"

Shariah "path"; Islamic law

Ulama religious scholars or clergy

Ummah Islamic community, refers to the worldwide Muslim community 


\section{INTRODUCTION}

\section{Muslim Integration and Assimilation in Northern Italy}

In this study, I examine the cultural implications of Muslim adaptation taking place in Italy. The study will seek to address how second generation Muslims, have sought to reconstruct an Islamic identity for the Italian context and how their efforts to acquire a newly formulated cultural identity has generated conflict within the Italian State and debates on national identity, human rights and the nature of their role in the public sphere. The aim of this paper is to also exam the dynamic of social transformation taking place in Italy today, due to increasingly demographic changes, resulting from a growing Muslim population within the past decade, generating religious and social conflict.

This is a case study exploring the intertwining cultural and structural factors which are contributing and preventing successful Muslim integration in Italian society. Additionally, this paper presents a conceptual analysis discussing the external and internal challenges facing second generation Muslims contributing to obtaining greater inclusion.

The context is also a historical one, spanning centuries, this longstanding relationship between Islam, the Muslim community engaging with European civilization, dates back fourteen centuries. As Erdenir (2010) points out, "Muslims have been present in Europe since the emergence of Islam itself, in the seventh century 
A.D."(Erdenir, 2010). The intent of this paper is not to conduct an exhaustive detailed analysis of the historical context, but to provide a general overview, highlighting the key periods in which Islam and Europe interacted through various periods in history. An overview of the historical context will help us gain a better understanding of the structural and cultural values indoctrinated within Islam, a system centered on community and fundamentally different to modern day secular Europe. Historically, the relationship between Islam and the West has been one of conflicting values, generating confrontation.

This study will briefly introduce a brief overview of the historical timeline, highlighting interaction between the early Muslim population and the Europeans, focusing on the Mediterranean region. The historical context is relevant to the concepts and theme presented in this study, influencing migration patterns, Muslim integration and provides a contextual framework and will contribute in gaining a better understanding of the contradictions. Given the complexity of the historical elements, this thesis intends to merely explain the contextualization of the existing differences between Islam and the West, related to the cultural and religious divide prevalent today.

The historical component of this study will permit a better understanding in framing the problematic relationship present today in $21^{\text {st }}$ Century Europe. The historical differences discussed in this narrative, validate my central argument, that cultural barriers preventing Muslim assimilation are additionally influenced by elements occurring throughout the historical period. Furthermore, competing visions, between the 
Islamic community and Western Europe, has far-reaching implications for modernity, impacting the religious divide, questioning the notion of secularization and generating competing interests between dominant Italian society with that of a religious minorityseeking greater inclusion.

Allievi (2003) illustrates:

The image that Europe has of Islam comes from a long history, profoundly rooted in every European country's encounter and/or clashes with Muslim countries. Whatever ways we adopt to understand and judge this long history (a task that will not be assumed here), it is clear to the observer that, most of the time, the analysis and opinions are about a confrontation between separate partners, which were - and probably still are - perceived as enemies standing in front of each other (Allievi, 2003, p. 141) [emphasis added].

My research in Italy, suggests that there are multi-layered factors that have impacted Muslim assimilation within Italian society, which is generally tolerant towards religious minorities. As such, my view is supported by the literature, that social, political and cultural factors have contributed to increasing measures adopted by the Muslim population, in promoting their cause for achieving greater inclusion within the Italian landscape.

My objective is to explore the social, political and religious conflicts generated by Muslim religious identity and its role within Italian society. Muslims in Italy are not a monolithic group; they come from many different national, cultural and ethnic 
backgrounds, though the majority comes from North African origins. In a recent study, Spena (2010) found that:

According to the annual Caritas/Migrantes report, there are approximately $1,250,000$ Muslims in Italy, comprising more than 30 percent of the total migrant population. The majority of these Muslims (58.4 per cent) originate from countries in the African Continent. Christianity is the principal religion of migrants in Italy with over 2 million followers); of these, Orthodox Christians represent the largest group $(1,130,000)$, followed by Catholics $(775,000)$ and Protestants $(140,000)$ (p. 162).

It is worth noting that according to Spena (2010) that "The relative size of each religious group reflects, and will indeed continue to reflect, the shifting flows of global migration (Caritas/Migrantes 2008) [emphasis added].

I have chosen this topic for several reasons. First, I was motivated in choosing my topic due to the general misconceptions of Islam and the negative perceptions of Muslim people, particularly in the West, resulting from a post September 11, 2001 worldview. The events that unfolded during the September 11, 2001 attacks were seen as a global confrontation against the West and its secular ideals. Hence, generating a kind of pandemonium and fear of Islam, resulting with negative stereotypes being formed with regard to Islam and the Muslim community in general.

My second reason in choosing this topic was influenced by my two recent study abroad trips to Cyprus. During my undergraduate program, I travelled to Cyprus twice with Professor Harry Anastasiou (in 2005 \& 2006). While visiting Cyprus, I was able to 
experience firsthand the cultural, political and social divide, influenced by religious identity and impacted by European nationalism. For Cyprus, the ethnic, national and ideological diversity between the Turkish and Greek Cypriots has created a long standing geo-political divide between the Turkish Cypriots and the Greek Cypriots, causing a once unified community to be divided geographically. Although there is a religious divide between the two communities in Cyprus, religion did not create the current polarizing conflict. The conflict is based on rival nationalistic policies of the Greek and Turkish mainland. My trips to Cyprus, followed by my academic research on this conflict, have brought to my attention how religious identity and ethnocentric nationalism have played a fundamental role in the shaping of Muslim integration in egalitarian societies.

The third reason that motivated my study resulted from my selection for an internship with the U.S. Department of State in Milan, Italy during spring 2008. While in Milan, I was tasked to work on a project funded by the U.S. Department of State. I was asked to brainstorm some ideas, in an effort to promote cultural awareness between Muslims living in Italy and the U.S. This project was facilitated under the U.S. Ambassadors Fund for Counter Terrorism and was developed for achieving the dual purpose of reducing crimes committed by immigrants in Italy, and to curtail the prospects of young Muslims becoming radicalized in extremist groups.

My ideas led to the proposal of establishing two separate groups of people participating in a cultural exchange program between Italy and the U.S. The two groups 
were composed of a Dearborn Michigan Muslim group and an Italian Muslim group from Milan. The main focus of these cultural exchanges was to facilitate a cultural exchange between three groups of Italian Muslims and three groups of American Muslims, primarily from Dearborn Michigan. Additionally, law enforcement exchanges were being planned, encompassing two teams from Italian law enforcement agencies, being sent to the U.S. -- requiring the teams from Italy to travel to the U.S. and meet with their American counterparts in carefully selected urban centers, such as New York, Washington D.C. and Dearborn, Michigan. This exchange also called for bringing two groups of Muslim community members and law enforcement agencies from the U.S. to Italy to engage with the local law enforcement and elements of the Muslim community residing in Northern Italy.

Through a combination of cultural exchanges, the overlaying objective for this project was to educate young Muslims by appointing them as integration facilitators, once they returned to their local communities. These young people would work in their prospective communities to assist the recently arrived, by introducing them on concepts of civil rights and to improve their awareness of the existing cultural differences in Italy.

Another goal of this project was to also create a grassroots umbrella organization, which would coordinate future cooperation by promoting additional cultural exchanges, creating awareness and expanding cooperation between the two groups in Italy. Moreover, this project was intended to reduce the likelihood of Muslim youth being lured into the ideological prospects of Islamic fundamentalism, resulting in 
recruitment by Jihadist movements. My objective was to introduce new ideas, by applying the concepts of "soft power", 1 where I was asked to promote Muslim cultural awareness between the Muslim communities residing in Italy and those residing in the U.S., through transnational cultural exchanges.

The issue of Muslim assimilation, cultural adaptation and the factors impeding Muslim integration will undoubtedly continue to pose greater political and social challenges for all European nations. Acceptance of this non-Christian religion and allowing for its integration for Italy in particular, will undoubtedly pose greater challenges for Italian society in the future as second generation Muslims seek to gain equal footing within Italian society.

My literature emphasizes the multi-faceted challenges facing Muslims in Northern Italy, regarding assimilation and efforts to achieving a greater public status and equal rights within mainstream Italian society. I will focus my research and thesis on the cultural adaptation of the Muslim community living in Northern Italy and address the dynamics affecting their integration within Northern Italian society.

\section{ISLAM - A GROWING PRESENCE IN ITALY}

Recently, the religious presence of Islam in Europe has seemingly become a controversial public debate. There are several reasons why this controversy and debate has generated into a conflict of ideologies. This controversy is further magnified by a

\footnotetext{
${ }^{1}$ According to Harvard Professor J. Nye (2002, June 8), who defines the concept of soft power as "coopting people rather than coercing them - for Nye the essence of soft power lies in values - in our culture and in the way we handle ourselves internationally"(Retrieved from www.theAustralian.com.au/)
} 
confluence of factors that has taken place within the past decade, resulting in a noticeable influx in Muslim migration on the Italian peninsula. The Muslim² population in Italy is highly heterogeneous, originating from many different countries and are predominantly from the African Continent. Through migration, they have disseminated into ethnic communities throughout the Italian peninsula. Interpreting these results, Spena (2010) notes "The immigrant populations is spread, albeit unevenly, throughout the country. Approximately 61 per cent of the population is concentrated in the north, while 25 per cent is located in the centre and 9 per cent in the south" (p. 162).

Lombardy in the North is the region where I conducted my interviews of my subjects for this study and it is also the region with the highest concentration of the immigrant population, followed by Emilia-Romagna and Veneto.

A key element inducing new debates has been the emerging controversy when framing religious identity. Among these factors, the growing visible presence of Islam vs. European values has re-emerged on the European political and cultural landscape, creating a conflict in ideals and requiring social transformation. Defining the role of Islam, in this era of globalization, where people from different cultural backgrounds are crossing trans-national borders in greater numbers, resulting in a mass movement of Muslim people into the European landscape, has caused for a renewed concern for cultural integration, adaptation and has created a need for the redefining of Muslim identities within a European context.

\footnotetext{
${ }^{2}$ For the purpose of this paper Muslims will be defined as people who have derived culturally and ethnically from the following countries; Morocco, Albania, Tunisia, Senegal, Egypt, Bangladesh, Pakistan, Algeria, Bosnia, Iran, Nigeria, Turkey, Syria and Somalia.
} 
For Italy, this increasingly popular phenomenon of Islam and Italian Muslim integration has drawn so much public attention recently, resulting in a cultural paradigm shift, leading to overlapping interests between the minority Italian Muslim community, with that of the majority Italian people, causing the Muslim community to seek and wanting to establish more equal footing within Italian society.

There are internal issues facing the Islamic community which is influenced by their own ideological, political and religious forces causing them to emerge as a community which represents competing visions with the dominant culture, thus, leading them to explore new ways on how best to construct an Italian Islamic identity.

For the Muslim community seeking to reconstruct there Islamic identity, while conforming to a Western dominant society, their efforts for obtaining social integration are being impeded, this is partially due to the very nature of Islam itself, which generates tensions between second generation Muslims and the dominant Italian population and is further impacted by the religious visibility that Islam poses publicly. Influencing this process are also contradictions found within Islam itself, which further complicates the process of achieving integration within a modern democratic European state. According to Spena (2010), the dynamics of the conflict within Islam are attributed to multiple factors, “...the conflicts between tradition and modernity, forms of democracy and the legitimacy of power, and conflicts between self-representation and other forms of representation" (p. 160). 
Within the European framework, having this prevalent visibility challenges European values, identity, further creating cultural and social obstacles. As a consequence of these demographic changes, a growing Italian Muslim population seeking greater equality, the dynamics surrounding the Muslim presence in Italy has led to an atmosphere of debate which has generated cultural challenges between European non-Muslims and Muslims seeking to integrate and reintroduce their Islamic identities. Subsequently, it is not surprising that Islam within the past fifteen years has become the second largest religion in Europe, validating a greater need for cultural integration and requiring social transformation for Europe and Italian society. In her recent study, Spena (2010) noted:

A further significant question is the search of Muslim communities for an authentic European and Western identity as part of their historical, political and cultural relationship with alterity. The overall question of migration, in fact, forces us to rethink the categories we use in comprehending our own identity, and to deconstruct our political, institutional, social and cultural understandings (Spena, 2010, p. 160).

In contrast to most of Western Europe, Islam has established a growing presence in Italy only within the past two decades, Muslim assimilation within Italian society remains relatively unchartered and a recent phenomenon. Unprecedented in its magnitude and scope, this increasing migration from Islamic countries has brought about a new dimension to Italian society, particularly within the public arena, requiring profound changes. Eventually, the presence of Islam and Muslim adaptation in Italy and within Italian society will shape and be shaped by a newly chartered Islamic component. 
The Muslim community is seeking to achieve greater status and religious freedom within a predominantly Catholic society, while attempting to insert itself within Italian society without compromising their loyalties to Islam. For many Muslims who reside in Italy, this process has become a daily challenge. This maybe partially due to the very nature of Islam itself and its visible presence, requiring a lifestyle that is often times unwavering, calling for strict religious conformity, known as Sharia. Although strict compliance to Sharia is not representative in Italy or within Europe by the majority of the Muslim population, it remains closer to Islamic tradition and a factor among Islamic religious teachings. Undoubtedly, Italian Muslims are also influenced by the mainstream Italian culture and Catholicism remains prevalent and maybe interpreted as a religious contradiction challenging Muslim values. This is not a one sided process, as shown by Rath, Penninx, Groenendijk and Meyer (2001), in their recent book "Western Europe and Its Islam." They state that Muslim immigrants are only one part of the equation, "the society around them also influences the process. The final form which Islam - with all its variants - assumes can be viewed as the result of consultation and conflict between all the different parties involved" (Rath, Penninx, Groenendijk, Meyer, 2001, p. 2). There are many factors which play a role in defining this interaction; some factors are related to Islam others are related to structural cultural influences.

My thesis will also examine, how descendents of Muslim migrants to Italy, whether first or second generation have intertwined into a cultural mix of racial, ethnic 
and religious groupings, lacking a unified Islamic community typically found elsewhere. Moreover, I will further illustrate how recent scholarly literature acknowledges that this new dimension, resulting from Muslim migration, has not only generated conflict in the public domain, but has required EU states to rethink a viable mechanism for integration. As noted by a prominent scholar who conducted a study on Muslim integration for Italy in 2008 , a central argument presented in my case study will be based on the perception of identity. In my paper, I will explore the dynamics of $2^{\text {nd }}$ generation Muslims seeking to preserve their Islamic identity. Toronto (2008) illustrates; "the important question of how many of the Muslim immigrants actually consider themselves Muslim, whether due to cultural identity or religious observance, also remains unclear and virtually unexplored" (Toronto, 2008, p. 62). For this reason, I chose to conduct my research in Italy and to examine the intricacies of this issue further.

Consequently, this study seeks to explore the relationship between the influences of Catholicism in Italy (although known to be remarkably open towards religious minorities) and the emerging Islamic Identity in Italy, inducing new debates on multiculturalism, national identity and social inequality.

I will seek to answer the following questions: "Does the rise of Islamophobia in Europe have a bearing on the cultural barriers affecting the second generation Muslims in seeking integration?" and "To what extent do we allow Italian Muslim integration and an emerging Islamic component interwoven into Italian society and greater inclusion of a growing Muslim presence within the Italian public sphere?” These are 
valid questions, which I sought to address while conducting my interviews and research in Italy.

Theoretically speaking, within Islam there is no separation between religion and state. Islamic law (Sharia) ${ }^{3}$ replaces secular governments. Many Muslims that have migrated to Italy, tend to embrace democratic values while seeking to retain their Islamic identities, they rely on community leaders, religious cultural centers and Islamic family law to guide their daily lives. Islamic law and its religious implications impact the Muslim community in a very public and noticeable way.

For example, Muslim women typically will dress modestly and refrain from revealing their female attributes by wearing a head scarf $(\text { hijab })^{4}$. The impact of Sharia, particularly for Muslim women requires a stricter adherence to dress and social interactions. According to Islam, veiling and the seclusion of women, where intended to protect, honor and maintain a distinction for women to adhere to. Typically, Muslim women are separated from men during social interaction, even at their place of worship.

Whereas, on the contrary, Italian society exhibits more openness and freedom of dress towards women. Women are extremely trendy, they dress extremely fashionable, wearing clothing that is somewhat revealing in public. This practice is not only socially acceptable, but desirable. Italian women social interaction with men is

\footnotetext{
${ }^{3}$ The literal meaning of Sharia is "the road to the watering hole," the clear, right, or straight path to be followed. In Islam, it came to mean the divinely mandated path, the straight path of Islam, that Muslims were to follow, God's will or law" (Esposito, 2005, p. 78).

${ }^{4}$ The veil or head covering scarf worn by Muslim women in public. "The Quran does not stipulate veiling or seclusion. On the contrary, it tends to emphasize the participation and religious responsibility of both men and women in society" (Esposito, 2005, p. 98).
} 
typically more open, intimate and visible in the public sphere. This profound interaction between men and women in Italian society seems to be embedded into the very fabric of Italian culture and presents a challenge for Islamic values.

Muslims today inhabit a vast land stretching from the Atlantic to the Pacific, with a significant presence in Europe. A historical presence of Islam is rooted in the Mediterranean region and Muslims today share multiple allegiances to religious interpretation, nationality, country of origin, culture, ethnicity and political ideologies. Will the reframing of second generation Muslim identities and their adherence to Islamic principles conflict with the generally tolerant Italian society? Is the resurgence of Islam in Europe, the practice of Islamic faith and ideology, truly compatible with European secularism, democracy and pluralism? In this paper I seek a deeper understanding of the conflict and provide answers for these compelling questions. My topic presents a complex phenomenon. Muslims in Italy are opposed to being treated as outsiders, but many also face barriers to integration within Italian society and are seeking greater inclusion in European society.

The purpose of this ethnography is to gain an understanding of the cultural differences that exist between the $1^{\text {st }}$ and $2^{\text {nd }}$ generation Muslims residing in Italy on the one hand, and the mainstream Italian population on the other. My research conducted in Italy, through interviews and my participation in the National Muslim Youth conference focus group in 2008-2009, known as 'Giovani Musulmani d'Italia' (GMI), will assist me in comprehending the religious and cultural conflicts which are prevalent. My 
objective is to gain a broader understanding of the internal and external challenges which seem to undermine the integration process of second generation Italian Muslims.

My overarching argument will be to validate the need for establishing social transformation, which I have experienced firsthand during my recent participation through interviews, direct observation and with my participation in a Muslim hosted focus group during my December 2008 trip to Italy. My engagement in the focus group discussions clearly demonstrated the cultural and religious problems faced by my research population. Particularly the need to redefine the Italian Muslim ethos. My study will seek to further explore the scope of the following question; "Will the reframing of second generation Muslim identities and their adherence to Islamic principles conflict with the generally tolerant Italian society?

I choose a qualitative approach for conducting my research, in order to gain a deeper more meaningful understanding of the issues affecting this conflict. My qualitative research was based on observation and on conducting interviews with my subjects, where I met with seven second generation Muslims and presented questionnaires addressing open ended questions seeking to measure existing conflicts related to religious identity.

In December 2008, I also participated in a four day national conference for Muslim youth residing in Italy $(G M I)$. During the conference, I participated in focus group discussions addressing the barriers to Muslim integration and religious adaptation within Italy, there were approximately 400 Muslim youth attending this conference. The 
Muslim youth, who engaged in a focus group dialogue, expressed how they felt marginalized living in a society that valued Catholicism and how their religious needs where being discounted. Validating this argument, Professor Sabahi (2009) recently stated, "Italy hasn't chosen a specific model yet for how it wants to deal with Islam" (as cited in Provoledo, 2009, p. 2). 


\section{CHAPTER ONE: HISTORICAL BACKGROUND OF ISLAM}

\section{Historical Background of Islam and its Influence in the Western Mediterranean}

During the seventh and eighth centuries Islam not only spread across tribal regions, but also throughout the more heavily urbanized regions of the Near East, North Africa, Spain and Persia. From its earliest beginnings, Islam represented more than just a religious order; it also meant a cultural and political movement, a system of governance. The development of Islam also signified the running of state institutions, governed by the caliphate (632-1258) and bound by the Sharia or Islamic law. It is necessary to review and analyze the history of Islam and its influences on the Western world in order to grasp a better understanding of Italian perceptions of Muslim civilization.

Early Islam obtained much of its philosophy, theology, literature and scientific knowledge from the Greeks. Esposito (2005) highlights how the development of Islam and state institutions (the caliphate, law, education, the military, social services) were all intertwined. From the earlier periods, beginning with the Medinan state in the early $7^{\text {th }}$ century, there are roughly seven historically significant eras covering a span of approximately a thousand years. For the purpose of this paper, I will cover highlights of Islamic history by placing emphasis on the Islamic empires and their relationship to the Mediterranean region. My historical analysis will focus on the changes that occurred within the Muslim community during the different periods, emphasizing the interaction between Italy and Muslim society. 


\section{The Caliphate (632-1258)}

The caliphate period which began in 632, appointed the companions of Muhammad and established them as the rulers of the Muslim empire. This was an era of expansion; a vast empire was created extending from Medina to Baghdad. Moreover, Islam meant the development of education, military and social services that were all intertwined with religion and central to the community.

Esposito (2005) states, "The early Caliphate established the pattern for the organization and administration of the Islamic state. Islam provided the basic identity and ideology of the state, a source of unity and solidarity" (p. 38). The caliph's authority and rule derived from his claim, that he was a successor of the Prophet Muhammad, and therefore legitimatizing his authority as head of the community.

The Caliph ${ }^{5}$ established political, military, judicial and fiscal control of the Muslim community. The Caliph's role within early Islamic society, served a dual purpose, he was the ruling governor for the community and the protector of faith, assuring that God's law would be followed and respected throughout the community. From the earliest of times, the Islamic community was a collectivistic society. The community was a brotherhood of believers, united by Islam and their faith, a society which was united by religion, rather than tribal origins, bonded by the religious teachings of the Quran.

\footnotetext{
${ }^{5}$ The title given in Mohammedan countries to the chief civil and religious ruler, as successor of Mohammed. Simpson, Weiner (Eds). (1989). The Oxford English Dictionary (2 ${ }^{\text {nd }}$ Ed., Vol. XVIII). Oxford: Clarendon Press
} 
Esposito (2005) wrote:

In general, the Arabs did not occupy conquered cities but established garrison towns nearby, such as Basra and Kufa in Iraq, Fustat (Cairo) in Egypt, and Qairawan in North Africa. From these towns, conquered territories were governed and expeditions launched. They were centered around a mosque, which served as the religious and public focal point of the towns. Conquered territories were divided into provinces, each of which was administered by a governor who was usually a military commander (p. 39)

The historical circumstances of the relationship between Islam and Christianity are complex and far more nuanced than generally portrayed. The general portrayal is one of direct continual conflict, however historically this has never been the entire story.

\section{The Umayyad Empire (661-750)}

The Umayyad period was established in 661, this newly formed ruling would transform the Arab sheikhdom into an Islamic empire, whose rulers would depend on religion to validate legitimacy and military power for stability and control. Muawiyah, who ruled the empire until 680, introduced the Umayyad era; this was a dynamistic era, dominated by Arab military aristocracy, they continued Islamic expansion pushing its frontiers into modern day Northern Africa and Western Europe. The Umayyad expansion brought Islam into the heart of Europe and introduced the first direct contact with what now constitutes Italy.

During this period, the Arab community experienced a form of modernization by extending its sphere of influence beyond the Arabian Peninsula. The capital of the 
empire was moved to Damascus Syria, the expansion of the Umayyad Empire seemingly coincided with the expansion of Islam, by extending its borders to Portugal in the West and as far as India to the East. It was during the Umayyad period, that a profound cultural shift took place for the Arab people, from desert nomads to a more cosmopolitan lifestyle. They were no longer just nomadic desert traders, but moved into urbanized, multi-ethnic cosmopolitan centers throughout the Middle-East and North Africa. Arabic became the official language, and their societies were ruled by Islam. As a faith, culture and identity, Islam has historically been a motivating factor around which people have mobilized, united and organized. The Arab community of this period, although centered on spiritual affiliation, developed into a more cosmopolitan Byzantine style society, symbolizing the new imperial age. We are able to grasp a better understanding of how this society was structured by noting Esposito's (2005) illustration:

In time, through a process of conversion and assimilation, language and culture, state and society were Arabized and Islamized. Arabic became the language of government as well as the lingua franca of what today constitutes North Africa and much of the Middle East. Islamic belief and values constituted the official norm and reference point for personal and public life (p. 40).

Generally speaking the Arabs did not occupy conquered cities but established garrison towns nearby, such as Fustat (Cairo) in Egypt and Qairawan in North Africa.

Organizational structures were centered around a Mosque, Islamic institutions and social interaction was greatly rooted in Islamic tradition. Clearly, this was a society 
built on Islam, governed by Islamic principles, even social interaction and gatherings were central to the local Mosque, and life in general was structured around the Quranic teachings.

\section{The Abbasid Caliphate: Islamic Civilization}

Following the Umayyad Empire, divisions within the Islamic community surfaced, Esposito (2005) notes that political, social, economic and religious grievances were viewed through the lens of an Islamic ideal, this ideal was relevant with preserving Islam and influenced all areas of life. During this period, several differences in ideology emerged, leading to opposition within the Islamic community and the forming of different factions, notably the Kharijites. Lewis (2001) found:

Since early times there had been sectarian differences within the Islamic world, between the mainstream Sunni form of Islam of which the Abbasid caliph in Baghdad was the legitimate chief, and the various sects, most of them loosely grouped under the heading of Shia, who challenged both the consensus of the Sunnis and the legitimacy of the Sunni Caliph (p. 21)

The Kharijites, who emerged during the time of the caliphate, were the first example of Islamic fundamentalism. They believed in maintaining a strict adherence to Islamic principles and practicing a form of "exclusivist egalitarianism". Esposito (2005) refers to the Kharijites as being somewhat extremists, "They were very pious believers who interpreted the Quran and Sunna (example) of the Prophet literally and absolutely" (p. 42). There world was divided into the philosophy of good versus evil, basing their ideals on Islamic faith and adherence to the Quran. For the Kharijites, acts were either good, or evil there was no in-between. Those who abided by Islamic principles and faith 
in the Prophet were seen as good and the non-Muslims who did not live their lives according to the strictest forms of the Quran, were the infidels and considered evil. There was no compromising of these basic principles.

\section{Islam and the West: The Crusades}

Historically, Christianity and Islam have sought to gain political, territorial and theological influences in the ancient world, often clashing over basic theological differences. As noted by Esposito (2005), "Islam's universal mission had resulted in the spread of Muslim rule over Christian territories and Christian hearts. While conversions were initially slow, by the eleventh century large numbers of Christians living under Muslim rule were converting to Islam” (p. 57).

From the earliest periods of Islamic history, Islam's theological message would clash by challenging Christianity and the authority of the Church. Although both Islam and Christianity shared monotheistic origins, the common belief in one God, for Christianity, Islam was seen as the religion of the sword, threatening Christians who lived under Muslim rule. In truth, early Muslim ruling authority made little effort to convert Christian populations. In fact as evidenced by the situation in Levant, Southern Spain, Sicily, among others, Muslim rulers actually preferred to retain Christian populations within Muslim communities, resulting in centuries of peaceful coexistence. On the other hand, the European response towards Muslim expansion was intolerant, requiring a need for intervention through confrontation. The prophet Muhammad and the legacy of Islam, was considered to be anti-Christian, resulting in Christian 
leadership feeling threatened by the rise and spread of Islam, particularly within the European sphere and Christian community. During the early Islamic periods, Christians and Jews had more personal and religious freedom, as opposed to the Byzantine Empire's one thousand year ruling.

According to Esposito (2005), by the eleventh century, Christendom's response to Islam took two forms: the struggle to reconquer Spain (1000-1492), Italy and Sicily (1061). This lead to the undertaking of several Christian holy wars, known as the Crusades (1095-1453). Christian armies, supported by the Pope and Monarch rulers of Europe, were summoned and fought the Muslims throughout the Eastern Mediterranean, Jerusalem and in the modern day Middle-Eastern region.

Esposito (2005) states, "Five centuries of peaceful coexistence elapsed before political events and an imperial-papal power play led to centuries-long series of so called holy wars that pitted Christendom against Islam and left an enduring legacy of misunderstanding and distrust" (p. 58). I will discuss this legacy of distrust and misunderstandings between modern Christian Italians, and Muslims who reside in Italy, later in my analysis.

\section{The Sultanate Period: Medieval Muslim Empires (1258-1629)}

From the earliest centuries preceding the death of Muhammad, Islam's existence and impact on the people of the Arabian Peninsula would have a profound influence, not only in the Muslim world, but on Western societies in general. To this end, this is 
primarily due to the successfulness of the Ottomans, who gained control of Constantinople (Istanbul) in 1453 and the conquest of the Byzantium. The Sultan Mehmet II, who ruled and conquered the Ottoman Empire, would unify the Muslim world, establishing the capital and its center in the cosmopolitan city of Constantinople. The Ottoman domain formed an early modern transnational system of governance and would rule the entire Mediterranean region, including North Africa and Asia Minor up until the late $19^{\text {th }}$ century.

The expansion of the Ottoman domain, extending from Asia-Minor in the East to modern day Morocco and Spain to the West, unified diverse communities and influenced greatly societies which were geographically in the Mediterranean region, thus, encompassing Christians, Jews and Muslims. Fuller (2008) illustrates, “As a cultural and moral force, Islam has helped bridge ethnic differences among diverse Muslim peoples, encouraging them to feel part of a broader Muslim civilizational project" (p. 51).

Despite the Ottoman rule forming a unified empire, through various different ethnic people and ancient western civilizations, two fundamental differences perpetuated between Islam and Christianity. First, Islam, as a world religion, arrived after Christianity and therefore claimed to supersede Christian revelation. Second, Islam fundamentally rejected the Christian doctrine of Christ's divinity, or in the Catholic 
theological reasoning known as the Divine Trinity ${ }^{6}$. By the eleventh century, Muslim rule and Islam as a religious force established a universal mission and moral calling, resulting in Christians seeking to convert to Islam. Many Christians living under Islamic order, were becoming somewhat Arabized, influenced by Arab culture and adopting Arabic language and manners. This occurrence created a problem for the Catholic hierarchy in Rome, by challenging its authority and would later result in a series of wars between the Christian crusaders and the Muslim armies.

\footnotetext{
${ }^{6}$ In theological use: "The three 'persons' or modes of being of the Godhead as conceived in orthodox Christian belief; the Father, Son, and Holy Spirit as constituting one God; the triune God (often the Holy Trinity)". Simpson, Weiner (Eds). (1989). The Oxford English Dictionary (2 ${ }^{\text {nd }}$ Ed., Vol. XVIII). Oxford: Clarendon Press
} 


\section{CHAPTER TWO: LITERATURE REVIEW}

\section{Introduction}

Since the establishment of the European nation states occurring during the midnineteenth century, mass movements of people across geographical space and national borders have clashed with competing ideals of national identity. This migration, particularly from Muslim nations, has marked one of the most profound and troubling aspects of demographic change in modern human history. The European Commission has sought to introduce and implement policies that would benefit the integration process regarding Muslim immigrants. Spena (2010) found that:

Already in 2005 the European Commission had produced a 'Common Agenda
for Integration' which underlined the necessity of 'emphasizing civic orientation
in introduction programmes [sic] and other activities for newly arrived third-
country nationals with the view of ensuring that immigrants understand, respect
and benefit from common European and national values' (CEC 2005: 5) (p. 173).

Within the past decade, the religious presence of Islam in Europe has seemingly become a controversial topic, generating considerable public debate. There are several reasons why the controversy and debate over Islam vs. European values have reemerged on European political and cultural landscapes. This thesis will confine itself to the controversy as it has emerged in Italy.

Perhaps, during this era of globalization and transnational border crossing, the increasingly growing phenomenon of Islam and Muslim presence in Italy, has drawn so 
much public attention and debate, requiring Europeans to rethink this changing dynamic, recognizing a need for assuming a newly designed social framework for integration. While there have always been immigrants coming into Italy for a wide range of reasons, the burgeoning numbers of Muslims practicing Islam is drawing a particular kind of attention, requiring Italians to rethink the social framework they have previously employed as they consider what it means to accept the incorporation of approximately one million Muslims into the Italian social fabric.

Regardless of a generally tolerant attitude towards migrants, the growing numbers of Muslim immigrants into Italy are a growing concern for Italian society. This may be due to the nature of Islam, the diverse cultural environments and the religious visibility of Muslims. In Italy, there are many factors which are challenging religious identity and impeding Muslim integration. The Islamic presence in Europe and the assumed Muslim identity possess different characteristics from Muslim countries, typically, $1^{\text {st }}$ and $2^{\text {nd }}$ generational Muslims maintain close cultural ties and community allegiances with their country of origin, outside of the European sphere. Some of these differences are a product of several factors; the negative impact of the media on Islam, the political opposition by the far right, known as the "Italian Northern League (Lega Nord)" and the hierarchical position of the Roman Catholic Church. I will examine how Islam, and the very nature of its public visibility, poses a challenge for European values, identity, further creating cultural and social obstacles. The emerging Muslim identity has generated an atmosphere of debate and generated conflict between Italian society 
and Muslims seeking to integrate and to reintroduce their Islamic identities within the European framework. Consequently, it is not surprising that Islam within the past fifteen years has become the second largest religion in Europe, validating a need for cultural integration and requiring social transformation for Europe and Italian society. In contrast to what has occurred in other Western European nations, Islam has established a presence in Italy only within the past ten to fifteen years.

As the numbers of Muslims increase, their integration into Italian society becomes a more obvious problem, bringing to light cultural barriers previously invisible to most Italians. Muslim integration and the existing cultural barriers for Muslim assimilation in Italian society, is a relatively new phenomenon. Unprecedented in its magnitude and frequency, increasing migration from Islamic countries has brought about a new dimension for Italian society, particularly within the public sphere.

In light of 9/11, with the Bush indoctrinization of the "Global War on Terrorism", the rift between the West and the Islamic world has been greatly amplified and has further invoked the differences that exist between Western ideals and the Muslim community. The impact of the U.S. strategy following the attacks of 9/11 has lead to a negative portrayal and a global misrepresentation of Islam. This narrow understanding of Islam is a product of multiple factors; mainly the media's oversimplification of Islam, the chaotic nature of "secular" and "religious" in a Muslim context, the emphasis placed by mainstream Western media on presenting Islam in a negative light. The misrepresentation of Islam, is also influenced by how extremists 
present the Muslim faith in an insular way to the world, thus, generating a lack of understanding of what it means to be of Muslim faith. This oversimplification of Islam, presented widely by the media and the narrow interpretation amplified by extremists, contradicts the true origins of Islam. Subsequently, this understanding challenges the broader historical tradition of Islam.

I will seek to explore the dynamics and implications brought about by the resurgence of Islam in Italy, which will require a restructuring or transformation of Italian society.

The literature is categorized into three principle sections, in order to address the three main areas of my study, encompassing both academic books and journals. First, I review the historical background of Islam and its influences on the Western world. Second, I review the literature on the current dilemma facing modern day Italian society, highlighting the challenges that second generation Muslims encounter with integration and in achieving equal footing within mainstream Italian society. Third, I review the conflict resolution theories related to cross-cultural conflict and present the conceptual framework endorsing the challenges that second generation Muslims encounter with the assimilation process. Through the secondary literature I will attempt to explore the modern day phenomena which directly impacts $1^{\text {st }}$ and $2^{\text {nd }}$ generational Muslims and keeps them from achieving their desired goals for greater inclusion. This will be accomplished by addressing the cultural barriers, represented by their allegiance to Islam, which contrasts with the dominant culture's values and their historical and 
underlying relationship with the Catholic Church. My study will examine the cultural differences related to religious identity, focusing on the challenges facing second generation Muslims, by investigating the opposing values between the dominant culture and the Muslim population. I have chosen my literature with the intent of unraveling this modern day conflict prevalent in Italian society leading to the marginalization of first and second generation Muslims seeking to achieve equal status within Italian society.

\section{The Historical Influences of Islam in Europe and Italy}

In contrast to most of Western Europe, Islam has established a growing presence in Italy within the past ten to fifteen years. Unprecedented in its magnitude and frequency, this increasing migration from Islamic countries has brought about a new dimension for Italian society, particularly within the public sphere. Muslim integration within Italian society is a relatively new phenomenon. Interpreting this trend, Spena (2010) found that "according to the annual Caritas/Migrantes report, there are approximately 1,250,000 Muslims in Italy, comprising more than 30 per cent of the total migrant population”. (Spena, 2010, p. 162). Subsequently, the majority of these Muslims (58.4) are from countries in the African Continent. Since the early 1990's, there has been a recent influx of Muslim migrants to Italy. Whether first, second or third generation, they have intertwined into a cultural mix of racial, ethnic and religious groupings, reintroducing cultural differences and creating a resurgence of Islam within the European landscape. Although Italy, a predominantly Catholic country and has 
historically held strong Christian traditions, recently a far-right anti-immigration political trend has gained popularity, thus further complicating the efforts for Muslim integration.

Despite this trend, efforts by newly established Muslim media publications and newly formed Muslim youth outreach groups, intended to improve Muslim cultural awareness among the mainstream Italian population, their efforts have been hampered by attitudes resulting from a post September 11, 2001 worldview.

The impact of September 11 $1^{\text {th }}, 2001$ was felt throughout the European landscape, causing confusion and invoking anxiety among Muslims and non-Muslims alike. The aftermath of these traumatic events, generated a tumultuous relationship between non-Muslims and Muslims, especially for the Muslim community residing in the West. Moreover, the U.S. reaction to $9 / 11$, leading to conflict in several Muslim countries has further amplified this modern day rift and has reintroduced a twenty-first century renewed clash between Islam and Western culture.

Almost every European country has provided troops of varying numbers to the conflicts in Afghanistan and Iraq. Italy, Germany, the United Kingdom and Spain have held sizable troop contingents in the conflicts in Afghanistan and Iraq following 9/11. These European countries involvement has exacerbated Muslim West relations and has invoked greater anxiety between Muslims and non-Muslims in Europe. 
This implied clash of cultures has generated negative stereotypes and perceptions of Muslims in Italy, raised anti-Muslim sentiments and introduced fears of Global terrorism. This process has been further amplified by the negative Italian media coverage, often times associating Islam with violence and terrorism, further magnified by a post 9/11 renewal of Islamophobia. This creates a dilemma for Italian Muslims who seek to establish a dual identity, acknowledging Islam as a religion of peace, while seeking to blend with the local culture. Erdenir (2010) went so far as to state, "At present, the gradual recognition of Muslims and the institutionalization of Islam are happening along with discrimination and hostility. But Europe has the cultural background and social mechanisms which enable the accommodation of different worldviews and values" (p. 40).

Challenges that Muslims face are related to dress, social issues, religious education and cultural differences, referred to by Erdenir as "a clash of lifestyles". In a recent article Povoledo (2009) interviewed Muslim magazine "Yalla Italia's" editor, Martino Pillitteri and wrote:

The message behind articles and blog posts like "To wear or not to wear a burkini?" and "How to match kaftans with jeans" is clear: it is possible to assimilate without losing a Muslim identity. We're separated by 10 meters, but culturally we're centuries apart" said Martino Pillitteri, Yalla Italia's chief editor. He said he saw the differences between his mission and that of Muslim conservatives as symbolic of the divide in Italy's Muslim population - one vision driving toward the past, the other driving toward the future. (para. 3) 
Recent literature and scholars acknowledge that this new dimension of Muslim migration has generated conflict in the public domain. This conflict has been further magnified by the cultural differences posed by religious identity, creating an atmosphere of competing identities and rivalry between the Christian dominant culture, and the Muslim minority population. Consequently, this process has incited new debates about multiculturalism, national identity and social equality. Most importantly, to what extent do Italians allow Muslim integration into Italian society and the public sphere? In this process, $1^{\text {st }}$ and $2^{\text {nd }}$ generation Muslims in Italy are opposed to being treated as outsiders. In light of contemporary realities, Muslims also face barriers to assimilation within Italian society and seek the same status as Europeans. In presenting the historical perspective of Christian-Muslim relations and to gain a better understanding of the cultural differences, it is imperative to go back and begin with the history of Islam as a world religion and to gain a better understanding of Islamic civilization, its relationship with Christianity and how Muslims and non-Muslims have coexisted together for centuries, living within the same communities during the era of Muslim rule (632 to 1736).

J. Esposito (2005), in his book, "Islam the Straight Path", explained:

The September 11 terrorist attacks against the World Trade Center and the Pentagon led some to signal a new clash in the twenty-first century between Islam and Western civilization. Others countered that it was a clash between the civilized world and global terrorism. For many the belief that significant progress had been made toward a better understanding of Islam and in ChristianMuslim relations seemed an illusion. September 11 re-animated ancient and more recent fears, animosities, and stereotypes. (pp. ix-x) 
His book offers a chronological perspective of the history and heritage of Islam, Esposito (2005) provides a comprehensive account of the origins of Islam, from the early centuries to modernity. The author illustrates the historical expansion of Islam, from its early origins in the Arabian Desert during the $7^{\text {th }}$ century to a global presence during the $21^{\text {st }}$ Century. Although Islam often times remains misunderstood, today Islam is a predominant world religion, encompassing fifty-six countries globally and is the second largest religion in Europe. The author acknowledges how the resurgence of Islam and the dynamic role that religion continues to play during the $21^{\text {st }}$ century, has led to cultural conflict for Muslim communities throughout the West. September $11^{\text {th }}$ and its aftermath, proved to be a tragic turning point for Muslims globally, resulting in abolishing the progress that has been made over centuries and undermining the relationships between Muslims and Christians in the Western world.

According to Esposito (2005), "For many the belief that significant progress had been made toward a better understanding of Islam and in Christian-Muslim relations seemed an illusion. September $11^{\text {th }}$ reanimated ancient and more recent fears, animosities, and stereotypes" (para 2). The aftermath of September $11^{\text {th }}, 2001$ resulted in the forming of a universal vilification of Islam and Islamic heritage, reigniting fears, resulting in the labeling of Muslims as the "other" and associating Islam to violence and terror. 
The media and its images portraying Islam as a religion of violence have generated negative attitudes universally. These attitudes have impacted mainstream society's perceptions on Islam and Muslims in general, often times ignoring Islam's true message, of strong moral responsibility and obscuring the commonalities that Islam shares with Christianity and Judaism. Although historically, problems existed between Muslim and non-Muslim communities from a perspective of peaceful coexistence, they have continuously faced issues surrounding religious identity and have sought to reconcile their differences through assimilation. These cultural differences have been further exacerbated and greatly amplified during the $21^{\text {st }}$ century in a post September 11 world.

Esposito eloquently states, "Understanding Islam in the twenty-first century requires an appreciation of the broader struggle for the soul of Islam". As in the past, the religion of Islam, both the faith and its practice, is a complex reality, $-\mathrm{a}$ multidimensional faith and community" (para. 4). A detailed comprehensive analysis is given on the origins of Islam, the growth of Islamic fundamentalism, its relationship to Saudi Arabia's Wahhabism ${ }^{7}$ a conservative Islamic ideal, and the influences of Islamic extremism morphing into a global jihad, all relevant concepts with understanding conservative Islamic ideologies.

\footnotetext{
${ }^{7}$ Esposito (2005) notes, Founded by Abd al-Wahhab (1703-92) (p. 118). A revivalist movement of Islam developed with the purpose of reintroducing a purified belief of Islam, a more literalist approach, emphasizing Sunna Islam.
} 
Bernard Lewis (2001) in his book, "The Muslim Discovery of Europe" illustrates the reconceptualization of the relationship between Muslims and Europe, shifting from the Eurocentric viewpoint, to one which recognized Muslims as active historical participants. The author presents a paradigm shift, in which a historical analysis begins with the establishment of Islam in the Arabian Peninsula during the $7^{\text {th }}$ Century, and presents a narrative by emphasizing the Muslim viewpoint of Western Civilization through the discovery of Europe. Historian Lewis (2001) encapsulates Islam's role during the early middle-ages, by presenting the theme of discovery and expansion westward from the Muslim perspective.

The author begins with the first Muslim incursions into Europe centuries ago. He covers Islam's expansion to the West through commercial trade and diplomatic relations and analyzes the historical relationship between the Muslim world and Christendom. Lewis (2001) continues, by highlighting the great counter-offensive of Western Christendom against Islam, followed by the resumption of a Muslim Holy War which led to the renewal and extension of commercial and diplomatic relations expanding throughout the Mediterranean region. The book continues by covering the post Middle-Ages, which perpetuates a new era for Muslim rule, with the rise of new Muslim monarchies in Asia-Minor, Iran and Morocco and their explorations of Europe. Lewis (2001) argues, that Islam and Muslims should not be viewed as passive objects to be acted upon, but rather as active historical players, who share commonalities with Christendom and are deeply rooted in Western civilization. Much has been written by 
Europeans on the discovery of Islam and the historical periods of Muslim rule. His book analyzes European history from a different lens, by presenting the Muslim exploration and their perceptions of Europe. Lewis (2001) notes, "But the relationship between Islam and Europe, whether in war or in peace, has always been a dialogue, not a monologue: the process of discovery was mutual" (p. 12).

Bernard Lewis (1993), in "Islam and the West" provides a historical perspective of Islam's relationship with Europe, covering a one-thousand four-hundred year period, beginning with the word "Islam" and its origins as a civilization in Arabia. This account covers the origins of the Islamic empire, its relationship with Christendom and illustrates the profound commonalities between the two civilizations.

Lewis (1993), states that Christianity and Islam, each perceived itself as the "bearer of God's final revelation to humankind, with the duty of bringing that revelation to the rest of the world" (para. 2). Bearing in mind this concept, each recognized the other as its rival, resulting in a long series of conflicts beginning with the Holy Wars, the jihād and the Crusades. The author provides a historical account of the Holy Wars, known as the Crusades and points out how these wars resulted in conquest and reconquest of empires, both in Christian and Muslim empires alike. This back and forth of conquest and expansion resulted in multiple conflicts and led to the overlapping of civilizations. Whether Muslims were part of the European empires, or under Muslim rule, the author presents the back and forth struggle and differences between the two civilizations, as they sought to coexist peacefully. Lewis (1993) notes, "In this long and 
-alas - unfinished struggle, the two civilizations have been divided by their resemblances far more than by their differences" (para. 2). He eloquently illustrates, how Islam, although superseding Christianity, maintains theological similarities with Judaism and Christianity. The author clearly shows how Islam asserts its own universal message and mission. He points out, how a key distinction of Islam is its belief in monotheism, thus, formulating its clear message from the word of the Prophet Mohammad, based on the scriptures of the Quran.

According to Lewis (1993), the second section of his book, is not so much concerned with the encounters between the two civilizations, but rather focuses on the perceptions arising from these encounters. He articulates a popular historic perception of Islam within Europe, from a scholarly perspective. His account is based on translations from Arabic into Western languages and discusses the Muslim invasions of Europe, generating conflict in the early centuries, between Christianity and Islam.

Lewis (1993) argues that, European civilization felt threatened by the notion of Islam's expansion, not only from the threat of conquering European held territories, but also more significantly by posing a threat from having European Christians converting to Islam. Lewis (1993) states, "For almost a thousand years, from the first Moorish landing in Spain to the second Turkish siege of Vienna, Europe was under constant threat from Islam" (p. 13). This is a period that spanned from 711 C.E. to 1683, ending with the second Turkish siege of Vienna. According to Lewis (1993): 
In Spain and in Sicily, Muslim faith and Arab culture exercised a powerful attraction, and even those who remained faithful to the Christian religion often adopted the Arabic language. It was this fear, more than any other single factor, which led to the beginnings of Arabic scholarship in Europe, to the discipline which centuries later came to be known as Orientalism [emphasis added] (p. 13).

Samuel Huntington (1996) provides an alternative position on world politics, by presenting a post-Cold-War era theme, in which a paradigm shift of power has resulted changing the dynamics of this conflict. The author asserts that we are experiencing a shifting balance of power, affecting the political structures of societies. Huntington identifies how a strategic focus has evolved following the Cold-War, whereas the new focus is on a civilization cluster, no longer on a particular nation. This is a new type of conflict which followed the Cold-War era, a conflict between civilizations, mainly between the West and the Muslim world. He introduces several political concepts, most noteworthy, he presents a theory which is dubbed as the "clash of civilizations", impacted by non-Western cultures, in which the balance of power ultimately is affected. The political structure of civilizations, has led to competing interests between Western powers and the non-Western world, this has been further amplified by a collision of civilizations, competing identities, political structures of societies and conflicts generated by the West seeking to establish "a Western brand of universalism."

Since the mid-nineteen nineties, Europe is no longer divided between East and West, and the threat of the Soviet era expansion of Communism has diminished, hence, reigniting past rivalries by generating a $21^{\text {st }}$ Century "Clash of Civilizations". This is a 
different type of conflict and it identifies a new form of enemy, where civilizations collide and greater emphasis is placed on religion and the differences between Western civilizations and the non-Western world.

Huntington (1996) attributes this paradigm shift, to a changing world order, in which we are experiencing a universal clash of cultures between Western society and "non-Western culture", suggesting a rivalry between Western dominance and the Muslim world. According to the Huntington (1996) model, this rivalry between the West and the Muslim world is further exacerbated by differences in cultural values. He attributes this distinction in culture as being greatly influenced by religion and identity, stating that we are experiencing a universal clash of cultures between Western society and "non-Western culture" which is representative of the Islamic world.

Huntington (1996) illustrates:

People have levels of identity: a resident of Rome may define himself with varying degrees of intensity as a Roman, an Italian, a Catholic, a Christian, a European, and a Westerner. The civilization to which he belongs is the broadest level of identification with which we feel culturally at home as distinguished from all the other "thems" [sic] out there. [emphasis placed] (p. 43)

More specific to individual perceptions and motivations within larger social phenomena, lays the ideals in which Huntington (1996) illustrates the important dynamic that civilization plays in defining culture and with establishing any given population's beliefs, social structures and values. Moreover, Huntington (1996) recognizes that civilizations may overlap and have no clear and concise boundaries. 
Over time, people may redefine their identities and the composition of civilizations may change somewhat. Huntington (1996) notes "that a civilization is thus the highest cultural grouping of people and the broadest level of cultural identity people have short of that which distinguishes humans from other species" (p. 43).

Some of the common elements which identify the characteristics of civilizations are defined by such elements as; language, history, religion, customs, institutions and by a more subjective self-identification of people. Huntington goes on to emphasize the importance of how cultures related to any grouping of people, continue to interact and overlap, despite the formulation of the nation-state in a post-modern era. Consequently, the underlying assumption Huntington (1996) presents is that, "the extent to which the cultures of civilizations resemble or differ from each other also varies considerably. Civilizations are nonetheless meaningful entities, and while the line between them are seldom sharp, they are real" (p. 43).

\section{Intercultural Conflict and the Influence of Culture}

Culture plays a definitive role in determining the relationship and interactions between people and establishes a frame of reference in which people may identify shared commonalities with (Avruch 1998; Singer, 1998; Ting-Toomey \& Chung, 2005). As noted by Singer (1998) in his synthesis of identity groups, "Each of us is a member of a finite number of different identity groups, but it is a comparatively small number compared to the incredibly large number that exist in the world" (p. 30). Consequently, Singer (1998) attributes the premise for establishing a person's cultural grouping or 
with determining a sense of belonging, to the "life-history" of an individual; typically this is the community that a person is born into. For the most part, a culture in which a person identifies with, is greatly influenced not only by a person's life experiences, but is also greatly influenced by ones parents; this is where the manifestation of attitudes, beliefs, language, values and a disbelief system perpetuates. These characteristics in determining culture also formulate a person's ties with a particular group. Singer (1998) emphasizes the importance of cultural inheritance and the influential role that parents have:

They [the children] will, in all probability, speak the language that their parents spoke; practice the religion that their parents practiced; support the political parties that their parents supported; and in broad outline accept most of the cultural perceptions that their parents accepted. (p. 30)

Through this general definition, not only is a person's culture influenced by his parents, but a person will perceive the world and formulate ideals very similar to that of their parents. This process is what makes a person part of the same broad cultural grouping in which their parents belong to. Perhaps one of the most influential aspects of culture is language. Sharing a language with others allows a person to identify with groups and share a sense of belonging to a broader community.

Singer (1998) notes, "Every culture has its own language or code, to be sure, but language is the manifestation - verbal or otherwise - of the perceptions, attitudes, values, beliefs, and disbelief systems that the group holds"(p. 29). Singer (1998) argues 
how language is a significant aspect which formulates a person's connectivity to a larger grouping. Additionally, there are many characteristics which influence "grouprelated perceptions", but, perhaps language remains the single most influential element defining culture. It is through language, attitudes, belief systems and values that we recognize and identify with an identity group. Each identity group develops its own pattern of perceptions and behavioral norms. This is how we categorize culture.

Avruch (1998) presents several concepts related to culture, stating that "inadequacies of culture" lead to an oversimplification of how culture is presented. Cultural conceptualizations are inadequate, because people tend to oversimplify the dynamics of culture. This is due to the generalization of culture and with failing to capture the complexity and diversity of culture. Avruch (1998) states that it is important to acknowledge that culture may also be influenced by "its connectivity, overtly or covertly, to a political or ideological agenda". Additionally, he addresses a typical misconception that culture follows a universal pattern and is often times oversimplified. He argues that coherence in culture is overstated. Emphasizing this misperception, Avruch (1998) notes how the degree of "cultural coherence" varies from culture to culture, in which, in some cultures assuming a lesser influential role. While there are varying degrees of coherence influencing culture, Avruch (1998) asserts that:

In any event, the degree and nature of cultural coherence, both within and across domains of social practice, are always empirical questions. In fact, to anticipate our discussion once again, it is most probably during times of intense or deeply rooted social conflict that cultural coherence is most problematical. (p. 13) 
In presenting his concept on culture, he emphasizes how culture is more than just a homogenous, or a superficial process, but rather it is conceptually connected to experiences by any social grouping. Avruch (1998) also recognizes how culture is conceptually connected to life experiences.

Research by Avruch's (1998) study found the following:

Individuals are organized in many potentially different ways in a population, by many different (and cross-cutting) criteria: for example, by kinship into families or clans; by language, race, or creed into ethnic groups; by socioeconomic characteristics into social classes; by geographical region into political interest groups; and by occupation or institutional memberships into unions, bureaucracies, industries, political parties and militaries. (p. 17)

Subsequently, Avruch (1998) points out that the more complex a society is, the greater the need for the concept of "subculture" in order to simplify its cultural mapping.

\section{$1^{\text {st }} \& 2^{\text {nd }}$ Generation Muslim Assimilation in Northern Italy}

The overarching theme presented by scholars, suggest that there are social, cultural and political factors which are impeding the efforts of $1^{\text {st }}$ and $2^{\text {nd }}$ generation Muslims to successfully integrate into the Italian cultural landscape. The contours for Italian society, with the growing presence of Muslim communities are changing, challenging the very fabric of a homogenous model. Researchers and academic scholars agree that as a consequence of a steady influx of immigrants from Muslim 
nations, Islam has become the second largest religion in Europe, requiring new efforts to achieve social integration into the Italian landscape, Allen C. (2004), Allievi (2003), AlSayyad (2002), Erdenir (2010), Hellyer (2006), Hunter (2002), Lappin (2007), Spena (2010) and Toronto (2008).

Allen (2004) asserts, "Whether the hyperrealistic 'Other' of urgent history is controlled or feared, remains to be seen, but what is for sure, is that in the foreseeable future, Europe's ‘Other' will remain undoubtedly Muslim”(p. 141).

Allievi S. (2003), the leading Italian scholar and sociologist on Muslim immigration and Islam as a religious identity, clearly acknowledges that the recent Islamic presence in Italy, which is partly due to Islam's very public visibility, has created many challenges for the Italian government and society seeking to accommodate this religious minority. The dynamics of Islam and Muslims seeking social integration in Italy, have become the central topic of Italian public debate, this is evident especially within cultural, religious and political circles and has created an atmosphere of conflict.

Allievi S. (2002), in his chapter, "Islam in Italy", emphasizes how the Muslim presence in Europe poses a dramatic cultural change that is no longer a temporary or transitory phenomenon. Italy within the past three decades has shifted from a laborexporting country, to a recipient of large immigrant populations from Islamic countries, the majority from Northern African countries. This emerging influx of Muslim 
immigrants to Italy, in a relatively short period, has materialized during the past fifteen to twenty years, resulting with a resurgence of Islam on the Italian landscape.

Consequently, this has generated Muslim cultural organizations and created newly established religious institutions, mosques, requiring them to establish a social network that had been previously nonexistent. The development of the immigrant communities in Italy, have certain characteristics that separate Italy from the rest of Europe. Mainly, these distinctions are due to the diversity of the countries of origin for Muslim immigrants, causing a lack of uniformity among cultural organizations. Although primarily Sunni, due to the country of origin for the majority of ItalianMuslims represented in Italy, the Islamic communities represent diversified movements and ideologies. He discusses the various aspects of Muslim organizations, unique to Italy, emphasizing the recent political and religious movements that are influenced by different Islamic ideologies with differing cultural tendencies. This is due to how Muslim migration manifested itself within the Italian context. Islam arrived as a byproduct of Muslim migration, quietly and its cultural presence increased in a subtle way. According to Allievi (2003):

The whole idea of shari'a (Islamic law) and fiqh (Islamic jurisprudence), as well as the idea of political power influenced by religion, and in many respects the entire Islamic theology - for instance, the majority-minority idea of society involved in the concept of dhimmi (the 'protected status' of Christians and Jews under Islamic rule) - simply presupposes that Islam is a majority in the population as well as a majority in power. This means that even if it is obvious from sociological evidence that Islam in Europe (despite the dreams of some Muslims leaders and the nightmares of some observers) is a minority, and will 
remain as such, at least for the foreseeable future, we often think of it as the 'big' Islam, the Medinise version [emphasis added] (p. 143).

AlSayyad N. (2002), presents a detailed analysis on identity and culture, acknowledging how the globalization process, due to an influx of immigration, has affected and resulted in conflicting views on how non-Muslim Europeans view the cultural aspects of Muslim populations, who are seeking to establish a new identity as European citizens. The author highlights how theoretically, for Islam there is no distinction between religion and state, thus, Muslims tend to reject secularism and seek independence in handling their affairs within their own communities and through the support of Islamic organizations, in accordance with Islamic laws. The author points out how Europe is increasingly becoming a multiethnic and multicultural society, creating an atmosphere of uncertainty on national identities, while Europeans seek to develop a new framework to integrate Muslim populations. The overarching debate is framed on placing Islamic culture vs. European culture, and that defining identity plays a crucial role in integration. The author notes that European culture is the dominant culture, while Muslims remain a subculture within European society and a byproduct of globalization.

According to Hellyer (2006), "it is difficult to find a country in the world that has absolute uniformity in terms of religious identity" (p. 329). His study, addresses the challenges faced by the European Union, with member nations composed of diverse religious identities and cultural minorities. The article further analyzes how the 
challenges posed to academics, NGO's and other entities are being dealt with by integrating and formulating protective policies within the EU that allow the integration of ethnic and cultural minorities. The EU has emphasized the development of imaginative models, in which the state would manage effectively the cultural, religious and ethnic diversities. The cultural issues that the EU must face, from allowing universal values, regardless of ethnicity, may conflict and challenge Muslim ethos. The subjugation of gender, for example with the recent banning of the niqab (veiling) in France illustrates the contradictions that Muslims must face in European society.

Many cultural and religious based issues are being evaluated by the EU member states, with particular emphasis on France and Germany; from the wearing of the hijab (headscarf), to the compliance of Muslim laws, to conformity in public schools. The issues that have confronted the European community with integrating ethnic minorities are being discussed in relation to other religious groupings, particularly within the context of the European Muslims. From his analysis two prominent questions emerge. Will we find Muslim communities residing in Europe, further challenging European mainstream identity in the $21^{\text {st }}$ century? Or will Europeans and EU integration view Muslim communities as legitimate subcultures, having perspectival differences that will hinder integration within European Society?

Toronto J. (2008), in his study on the prospects for integration of Muslims, explores the social dynamics and implications taking place in Italy, emphasizing cultural identity and religious observance as an area in need of further exploration. In 
his article, Toronto (2008) highlights the relationship between Muslim immigration and Italian society's willingness to accommodate and integrate this new wave of religious diversity. The author addresses the challenges posed for Italy by examining the social, political and religious conflicts resulting from mass immigration of Muslims seeking to establish integration within the Italian public sphere.

The author notes, that the recent influx of new Muslim populations in Italy has developed into two phenomena. Migrating Muslim youth are seeking to establish their own place within Italian society, seemingly reconstructing their own Islamic identities, within the context of Italian society. Consequently, the increase of Muslim presence has caused Europeans to rethink their own identities as European Union (EU) member citizens, and with their acceptance of religious minorities. Italy, although secular and tolerant towards religious minorities, seemingly holds a mistrust of Islam within Italian society. This is partially true due to two primary reasons. Firstly, Italy's extensive media coverage of Islam and Muslim communities tends to be bias and inaccurate and secondly due to the political and religious influences of the Catholic Church hierarchy. These attitudes are in conflict with Muslims and Islamic organizations which attempt to promote their cause in the public sphere. Islam and religious practices are more visible in the Italian public domain, and this affects the role of second generation Muslims in having to reconstruct their Islamic identity to adapt to the Italian context.

\section{The Institutionalization of Islam and Cultural Adaptation}


More specific to perceptions and motivations of the individual, within the larger context, there is a constant demand for establishing a greater presence of Muslim institutions in Europe. According to Rath, Penninx, Groenendijk, and Meyer (2001), the widespread introduction of Islam into Western Europe, occurred with the increasingly arrival of immigrants from North and West Africa, Asia and other distant Muslim countries. Rath et al. (2001) addresses how "For some time the Islamic religion led a 'hidden existence' in countries such as Great Britain, Belgium and the Netherlands, but this has gradually altered with the growth of a whole range of Muslim institutions (Rath, et al, 2001, para. 1).

A broader problem exists across Europe for the incorporating of Muslim institutions within civil societies, coupled with a growing need for allowing them to establish and expand their religious and cultural institutions. In their book, Rath et al. (2001) note that "From Muslim communities there is a constant demand for the recognition of their religion and its institutions; however, the responses of the receiving societies have seldom been straightforward, despite freedom of religion being firmly established by law" (Rath, et al, 2001, para. 1).

For the United Kingdom, the familiarity with Islam and the presence of Muslims within British society has had a longstanding tradition. This is due to two primary reasons further corroborated by Rath et al., the historical influences of British colonial expansionism and the British presence in the Indian sub-continent. The British administration, known as the East India Company, began recruiting Muslim seamen 
over three centuries ago. During the mid-nineteenth century; this process resulted in many Muslims settling temporarily in the United Kingdom. Lewis highlights the following:

After the opening of the Suez Canal in 1869, Muslim seamen from the Yemen and Somalia followed. Muslims also emigrated [sic] to the United Kingdom because of trade, and to follow higher education and Muslim centres [sic] grew up, particularly in London, Liverpool and Woking. Towards the end of the nineteenth century the first mosques were built for these partly temporary, urban communities. (as cited in Rath et al, 2001, p. 227)

During the mid nineteenth century, the nature of the Muslim centers began to change, due to the arrival of increasing numbers of a migrant labor force from the Indian Sub-Continent, now modern day Pakistan. In the late 1960's the demographics began to change, with the arrival of their wives and children. With the increasing migration of the Muslim labor force and their families, more permanent Muslim communities in several prominent British cities began to emerge. According to Rath et al (2001), "more permanent Muslim communities gradually came into being, and the need for places of worship and religious instruction increased" (p. 128).

Rath et al (2001) found "Immigration from North and West Arica, Asia, the Caribbean and elsewhere has brought with it a massive influx of Islam into Western Europe" (p. 259). For a long time the Muslim communities in Europe have had a rather 'concealed', a somewhat unnoticed existence, but Islam has proven to be mobilizing force. Driven by the need for establishing a greater presence, the Muslim community 
has progressed into a social mobilization, seeking greater religious recognition through the expansion of religious institutions.

The Muslim community is seeking to establish a larger identity and desiring a greater awareness within European society. The author suggests that there is not a single straight forward response by European governments for these communities to establish greater influence within the public domain. This may be due to the fact that the Muslim community historically, has maintained multiple-identities; up until the twentieth century, they were viewed by nationality, whether Pakistani, Yemeni or Bengali.

Today, nationality assumes a lesser role, as Muslims seek in having their identity recognized in the context of Islam and in having their identity recognized within the broader framework of society. Western European countries are all democratic societies, particularly under the framework of the European Union. Within the context of the EU, a great deal of emphasis is placed on democratic values, respect for human rights and freedom of religion. Consequently, the Muslim community, regardless in which European nation they reside, are seeking to gain more religious concessions, equal footing within society through recognition of religious, Muslim institutions and by gaining greater inclusion for their religious beliefs.

According to Roy (2004), "Globalised [sic] Islam refers to the way in which the relationship of Muslims to Islam is reshaped by globalisation [sic], westernisation [sic] and the impact of living as a minority" (Roy, 2004, para 1.). More specific to 
perceptions and ideological motivations of the individual, within the larger social and economic framework, lie the ideas of Oliver Roy (2004) and his theory on the relationship of Muslims to Islam and how it is being challenged by Westernization and by the economic implications of Globalization. He stated, "The issue is not the theological content of the Islamic religion, but the way believers refer to this corpus to adapt and explain their behaviours [sic] in a context where religion has lost its social authority" (Roy, 2004, para 1.).

As people try to hold on to a semblance of their cultural traditions and religion, they tend to turn to religion as a frame of reference for structuring their daily lives, whereas globalization as an economic structure assumes a lesser role and does not resonate with this aspect of the population. It's not about religion entirely, but the Italian Muslims are using the religious texts to explain their behaviors and social norms. Culture and religious revivalism are a valid argument not to conform to the economic dictates of globalization and with trying to appeal to a broader group.

Roy (2004) theorizes how Islamist movements were running out of steam as a revolutionary force, thus leaving them with two compelling choices, conformity within the framework of the modern nation-state or choosing a society governed by the Ummah, based on Sharia. The later choice would be to assume a more conservative representation of Islam, referred to as "neofundamentalism". The dynamics for the Muslim community residing in Western Europe are culturally different, they are a minority, considered migrants and seen as outsiders by the Europeans. Here, the 
Muslim community places a greater emphasis in using Islam and its unifying factors in having a greater voice within their societies. By placing Islam into a broader framework, this process unifies the Muslim community, where they assume a more unified voice, greater political influence, enabling them to address issues which are shared by their community.

Within the framework of Islam, political and parliamentarian movements have emerged in Europe, advocating egalitarian and more liberal ideals, these movements have sought a democratic structure for governenance turning to a form of religious revivalism, in an effort with creating a more liberal civil society. The desire for establishing liberal and a more democratic process for their society, seemingly clashes with a more typical authoritarian ruling. Many Islamic states are ruled by authoritarian regimes. For example, these regimes are supported by the West: Yemen and Jordan -although they remain categorized as secular states. They are also influenced politically by conservative Islamic ideals, this structure of governance based on Islamic principles are sought by conservative Imams or religious leaders. The authoritarian states' absolute control has been a principle obstacle for achieving democracy and for implementing political reforms. The states authoritarian control has prevented and presents a major obstacle for a more democratic process to take hold, this has been a typical pattern, rather than having the Islamic groups or the conservative Islamists, who seek to build a state structured by their national parties based on Islamic ideals.

Interpreting this process, Roy (2004) notes: 
Notwithstanding its internal dynamic, Islamism (the building of an Islamic state) has little appeal for many Muslims who have no desire to be involved in such a project because they are uprooted, migrants and/or living in a minority. These Muslims experience the deterritorialisation [sic] of Islam. When they turn to religious revivalism, other paths, including neofundamentalism, appeal most strongly to them. (p. 2)

In his narrative, Roy (2004), identifies and presents a cultural dilemma for the $1^{\text {st }}, 2^{\text {nd }}$ and $3^{\text {rd }}$ generation Muslim migrants who reside in the West. His viewpoint is extremely relevant for Muslim migrants who reside in Western Europe. He describes this process by addressing how the Muslim youth who reside in the West, have an appeal for rejecting the values established by Western governments. Contradictions arise, Muslim youth are faced with redefining their loyalties outside of a traditional Muslim context and seek to establish their political and social lifestyles based on Islamic fundamentalism and on more radicalized forms of Islamic viewpoints. Thus, the appeal for neofundamentalism, particularly among the youth becomes more likely. Roy (2004) states, “neofundamentalism has gained ground among rootless Muslim youth, particularly among second- and third-generation migrants in the West" (p. 2).

Although these tensions related to identity and belonging for $2^{\text {nd }}$ and $3 \mathrm{rd}$ generation Muslims are not representative of the majority of the Muslim youth residing in the West, including Europe -- however the inclination in leaning towards radicalization and supporting militant groups, such as Al Qaeda remain a factor. He further illustrates how, "these Muslims do not identify with any given nation-state, and 
are more concerned with imposing Islamic norms among Muslim societies and minorities and fighting to reconstruct a universal Muslim community or ummah"» (p. 2).

Fundamentally, his hypothesis places the issue of multiculturalism and cultural integration into a different context. This argument presents the ideal of maintaining your cultural identity as a means for rejecting any form of acceptance of Western society. Resulting with a segment of the Muslim youth, following a conservative doctrine of a more fundamentalist form of Islam based on Salafi ${ }^{9}$. For the Muslim youth who follow this conservative narrative, they are likely to resort to jihadist militancy and rejecting the West and the Western secular model.

\section{The Presence of Mosques and Islam Publicly}

Italian sociologist, Allievi (2009), recently completed a formal study for the Network of European Foundations (NEF). This study was based on newly compiled research, focusing on European countries, analyzing trends on detailed national overviews. His study focuses on the cultural challenges posed by European perceptions and interpretations of Islam within Europe as reflected in the disenchantment over the building of Mosques and concern with the increasing Muslim public presence. His recent study found that the presence of Islam within Europe's public domain not only provokes, but creates an atmosphere for debate, generating tension, influenced by a wide range of reasons. Some of the reasons amplifying this tension are due to historical,

\footnotetext{
${ }^{8}$ Islamic Community refers to the worldwide Muslim community (Esposito, 2005, p. 276).

9 "Ancestors," the first generations of Muslim community; because of their proximity to the Prophet Muhammad, their beliefs and practice are considered authoritative (Esposito, 2005, p. 275). 
cultural, religious, political and social implications surrounding a symbolic presence of Islam, within a public space.

Although there are several characteristics which contribute to the conflict and promulgate tensions, the central theme of this study is centered on the dynamics of the conflict over Mosques and the presence of Islam within the public domain. His empirical research analyzes EU countries, in which scientific literature is least abundant and somewhat unchartered.

Alleivi (2009) highlights the following point:

- in particular, cases of discrimination towards certain minority religions or religious beliefs, some of which have even come before the European courts - in no country and in no other case has the opening of places of worship taken on such a high profile in the public imagination as the question of mosques and Islamic places of worship. (p. 7)

As illustrated in Alleivi's (2009) study, his hypothesis introduces a specific dilemma, by presenting 'Mosques' and 'conflict' synonymously as if each compliments the other. He further states how the pairing of the words 'conflict' and 'Mosques' we assume a multi layered interpretation as to the specific dynamics of the conflict presented in Europe today.

According to Allievi (2009), the pairing of the two words, seemingly go hand in hand, producing specific dynamics in relation to conflict, of the seven EU countries studied, three of which were in the Mediterranean region and the nature of the conflict 
varies, depending on the historical influences for that country. For Spain and Italy, experiencing relatively new immigration from Muslim countries and due to the memory of historical Ottoman domination, the perceptions surrounding the building of Mosques varies. The challenges that this phenomenon poses is somewhat different than Northern EU countries. He states, "Mosques and 'conflict' are already two words that directly express dissonance, the idea of a problem" (Allievi, 2009, p. 9).

Nationalism and cultural interpretations also influences this problem, the public nature of Islam in itself, seemingly imposes on European and Italian society.

Allievi's (2009) highlights the following:

On the other hand, Islam and Europe (or Islam and individual nations, or Islam and cultural interpretations of their respective national self-definitions, variously defined as Britishness, Italianitả, identité républicaine, etc, depending on the country) are the main interpretative categories that arise from the collision of the first pairing. (p. 9)

In his example, Allievi (2009) found that, "The first pairing is local, the second global..." (p. 9). He examines the historical relationship between Islam and Europe, and characterizes it as being long, complex and asymmetrical. Allievi (2009), maps this historical context of this relationship by brilliantly categorizing this process into five phases: Phase 1; 'the first ten centuries on the expansion of Islam, symbolic of the Crusades'. Phase 2; 'European dominance of Muslim lands, highlighted by the Napoleonic expedition to Egypt (1798), the age of empires and colonization of the Muslim world'. Phase 3; 'Islam begins to spread to Europe through migration. During 
the period of post world war reconstruction and economic boom, beginning in France'. Phase 4; 'The emergence and the manifestation of Islam in Europe, where the gradual process of integration begins, initially in the workplace, subsequently in a more social and political context'. Allievi (2009), emphasizes the present day 'fifth-stage' as, "European Islam, The result of this process should be the formation of a genuine European Islam, with its own pronounced identity different from the Arabic Islam or that of other countries and cultural areas of origin" (p. 11).

He further argues for a gradual normalization of the management of religious pluralism. Allievi (2009) characterizes the current situation as on in which religious and cultural pluralism are seen as a "sickness" by European society, which ultimately needs to be viewed as the normal condition of the body politic. He asserts that religious and cultural pluralism within Europe need to be seen as "normal".

Allievi (2009) noted, that this is broader conflict, which goes beyond the building of the Mosques, referring to Huntington's 'the clash of civilizations', where Huntington's narrative formulates a "general politological theme of nemicus/hostis". Additionally, he further draws a coalition, by defining the conflict between Islamic culture and the West, by presenting Huntington's theoretical paradigm, as a clash between cultural identities:

The ever present difficulty in distinguishing between xenophobia and Islamophobia; the ambiguous love-hate relationship with the West, its values and the way of life that characterizes some sections of the Islamic presence: all are elements of this relationship as well as a continual reminder of questions and 
answers surrounding identity and contraposition: ego versus alter. (Allievi, 2009, p. 94)

\section{The Role of Nationalism}

Nationalism plays a pivotal role in determining the potential dynamics between inter-national and inter-ethnic relationships. Within the framework of nationalism, the nationalist narrative, portrays a grandiose image of the nation, unifying a population, where historical achievements of glory and greatness are greatly magnified, capable of mobilizing its citizens in participating in a national calling for achieving a 'grandiose future'. Rusen explained:

It cultivates a mono-centric, narcissistic concept of the nation's life-world, a teleological perception of the nation's history and an asymmetrical distribution of positive values and rightness identifying the "good" with one's own nation and the "bad" with that of "the other", particularly of "the enemy other". (as cited in Anastasiou, 2008, p. 83)

According to Alter, the nationalist narrative of J. Gottfried Herder and Giuseppe Mazzini found, that the phenomenon of nationalism assumes a divine form, capable of unifying people and with leading humanity to a path of achieving universal peace (as cited in Anastasiou, 2008, p. 82). This world view on nationalism, has mobilized entire nations during modern times, unified people in establishing a common goal, generated unquestionable loyalties for their respective nations. Under a more general definition, the notion of nationalism has placed the nation above all individuals and led people to 
violence and war, in the name of the nation. Historically, nationalism has led European nations to fighting two of the most destructive wars during the twentieth century. While the old school concept of nationalism is obsolete in most of Europe, strong ethnic and regional identities remain important. Other European scholars have interpreted nationalism as a legitimate moral and political phenomenon, capable of unifying a population into a national cohesive body countering the spread of globalization. However, political groups have used nationalism as an intolerant and somewhat destructive force, often associated with totalitarian and authoritative forms of governance. This narrative, categorized the phenomenon of nationalism as a destructive force, capable of dividing societies and with pursuing a narcissistic political agenda.

The reality is that nationalism becomes a dangerous force, when it becomes a tool for the state in mobilizing its people in pursuing an agenda, in achieving a political ideology which may encourage xenophobia and may create a "culture of collective narcissism". The nationalistic agenda is power-driven, self serving placing the interest of the nation-state above all individual needs. Within this narrative, a nation can revert to justifying their military strength and pursue its moral standing by adapting lethal force in order to achieve its goal of dominance.

Smith argues, "One of the powerful ways in which nationalism becomes historically instated is through its presumption that the nation is sacred - an attribute that many liken to a kind of secular equivalent of the Church. Smith (1993), an advocate of nationalism, speaks of the nation as being a religious surrogate (as cited in 
Anastasiou, 2008, p. 83). Nationalism, often times has the ability to mobilize a people, a nation and by representing a common interest, capable of giving a nation and its people the power and motivation for conducting warfare, even by assuming lethal means. Within this context, nationalism becomes a polarizing force, capable of dividing society and creating a culture of "us" versus "them". Anastasiou (2008) went so far as to suggest that, "Furthermore, nationalism has been viewed as a sinister force that has contributed to the globalization of conflict, while rendering globalization a conflict-proliferating process" (p. 82).

Under the premise expressed in 'Nationalism as a World View', Anastasiou (2008) found that, "The emerging field of study that is directly concerned with peace and conflict phenomena furnishes numerous theoretical and practical approaches. Among these is, Conflict Analysis and Resolution (CAR), which focuses on understanding and the structural dynamics of conflict through Conflict Resolution (p. 82)

According to Anastasiou (2008), by applying the concept of Conflict Resolution, where the emphasis is placed on perspectives, processes and structures that empower and facilitate the resolution of the conflict can be implemented. His analysis further suggests that through the process of Peace Studies (PS), where the emphasis is placed on understanding and with fostering the structural dynamics of peace. He further illustrates that, through the use of (PS) and by utilizing Conflict Resolution, a process can be achieved in which we formulate three basic developments; peace-building, peace sustenance and institutionalizing peace. By these means, we are able to refocus on 
resolving conflict through the lens of what constitutes a society and culture of peace.

This hypothesis can be further corroborated by addressing the dynamics of a protracted conflict and especially with addressing patterns related to ethno-nationalist conflicts.

According to Anastasiou (2008):

A suggested hypothesis for understanding why they have tended to be intractable is that in addition to the objective complexities that have historically permeated them, ethno-nationalist conflicts have been driven by well-configured, all-encompassing, and largely assumed world views that intimately associate a set of presumed supreme, ethno-national values and the right to employ force/violence in their name. (p. 83)

Moreover, one of the principle theories presented is on the nationalist view of community and identity, where a restrictive 'mono-ethnic' view emerges. Anastasiou (2008) explains that, "Nationalism either defies justice and democracy in the name of the nation or constricts democracy to an exclusively intra-national/intra-ethnic polity", this ideology is contrary to the EU agenda on promoting human rights and contrary to the notion of expanding community, by promoting cultural integration. Within the nationalist narrative the blueprint of multiculturalism becomes a problem because this narrative promotes a mono-ethnic culture. Specifically they do this by not integrating other ethnic-groups.

Anastasiou (2008) explained:

Being ethno-centric and intra-national, the nationalist perception of community gravitates toward the polarization of ethnic groups with and between societies by its exclusivist notion of identity and the hard psycho-political and territorial 
boundaries it strives to establish between the ethno-national "in-group" and the "out-group". (p. 89)

Within the framework of Conflict Resolution Analysis (CAR) and CR, it is important to note that the emphasis is placed on promoting a sense of community, by 'forging domestic inclusiveness of sub-national identity groups' and by seeking international engagement, by adapting 'functional and democratic inter-sate relations'.

Although tensions between ethnic groups are prevalent in Europe, instilling such trends as xenophobia and Islamaphobia, that contradict EU initiatives for pursuing the implementation of Peace building. They are contrary to instilling the notion of community building and with encouraging multinational representation through institution-building. Nationalist and ethnocentric tendencies, contradict EU policy on promoting human rights and with promoting a broader sense of multicultural assimilation.

Rusen (2004) explained:

This is not to suggest that there are no tensions between identity groups or current of xenophobia in the EU, but rather that under conditions of peace and wellbeing, identity formation and sense of community have broadened to encompass multi-cultural and inter-national configurations. (As cited in Anastasiou, 2008, p. 90)

His analysis suggests that by enriching and broadening of identity formation, this process formulates a sense of community that reinforces a renewed outlook by 
including the 'other' and breaking away from historical notions of adversarial constructs and ethno-centric narratives. By placing the nation state in a grandiose fashion the nationalist narrative, leads to the glorification of a mythological state, encourages wars and heroics and creates a false sense that 'all that is good is attributed' to one's own ethno-national community. This pararadigm of placing the nation-state over community is contrary to integrating the 'other' or any ethnic group outside of the dominant culture. It contradicts the principles of an inclusive, balanced society that is 'reality based', reflecting the EU's desire of establishing a multicultural approach for developing community. Bearing the historical consequences of nationalism, we are better able to cope with the imaginary construct presented by nationalistic historiographies, where the nation-state becomes absolute.

\section{Conclusion}

The existing literature is relevant in identifying and suggesting a profound dilemma facing Europe, the European Union (EU) and includes the Northern Italian landscape today. The dilemma involves competing interests between Islam and the European lifestyle. This conflict dates back to the rivalries between Christendom and

the Muslim world first appearing during the $11^{\text {th }}$ century, with Christendom mobilizing armies, in its attempts with reconquering Spain, portions of Italy and Sicily, these medieval Holy Wars were known as the Crusades. Today, the global relationship between Islam, the Muslim world and the West, is much more profound and complex, there are several reasons why this is so. Perhaps the most noteworthy theory that 
emerged seventeen years ago, when "The Clash of Civilizations" was first introduced by Harvard professor Samuel Huntington (1993).

In Huntington's narrative, a newly formulated hypothesis emerges; his narrative suggests that a conflict in civilizations exists, that this conflict has generated a profound division between the West and Islam and that this conflict is based on the premise of cultural differences. Although Huntington (1996) acknowledges, that the principle actors influencing global affairs will remain the 'nation state' in the modern world, this new post-Cold War world view, will continuously be dominated by the differences posed between nations and between groups of people of different civilizations. The Huntington model has been further corroborated by the events which took place on 9/11, leading to the reemergence of Islamic fundamentalism on the international stage and by revalidating Islamaphobia.

The Huntington world order seemingly conveys a culture of "collective narcissism' by presenting the "exclusivist notions of belonging", presented in professor Harry Anastasiou's chapter on "The Historical Record: Nationalism in the Literature"(2008). According to the Huntington notion, a narsacistic approach, which is "power driven and self-serving" emerges, this approach leads to the escalation of conflicts. Huntington's theory, in suggesting the "us versus them" mind-set, which had been previously played out during modern World Wars in Europe and more recently during the Cold War with Soviet Communism, falls short with the adaptation of Conflict Analysis and Resolution (CAR). After the fall of the Soviet system, where 
former Eastern bloc countries our now EU member states, this outdated model has now shifted and evolved by now placing the "us versus them", suggesting a rivalry and the notion of competiveness, between the West and Islam.

Within the framework of Conflict Resolution, when we start drawing these absolute and stereotypical notions of people, by framing different cultures or different civilizations, we escalate conflict and create the notion of "us" with all that is good, and "them" with all that is evil, validating an enemy.

Huntington's theory in collaboration with current world events, brings to mind the following question, 'is it right to define the world within an ethnocentric paradigm, by neatly packaging people into categories, into the "us versus them" framework?' Contrary to the Huntington narrative, Esposito (2005) introduces a more reality based, polished world view by presenting the Islamic framework, where Islam has proven to be a valid force in countering European imperialism and with adapting a revivalist movement since the late eighteenth century. Esposito's (2005) model, challenges directly the Huntington notion, where the Muslim community seeks to respond to the adversarial challenges brought on by external forces, seeking to disrupt Islamic faith and social order.

Compelling in his world view, Esposito (2005) illustrates how a revivalist movement has been reintroduced for the Muslim world and eloquently presents an outlook in line with the Muslim world view: 
Islamic modernists reinterpreted Islamic sources to obtain new answers and to assimilate some Western ideas and institutions. Islamic modernism influenced attitudes toward Islam regarding both its past significance and its modern relevance. Its emphasis on Islam as a progressive, dynamic, rational religion generated a sense of pride, identity, and conviction that Islam was relevant to modern life. (p.15)

Within Huntington's (1996) setting, I see a danger with scholarly literature presenting a philosophy which may validate this asymmetrical world view. By presenting the "us versus them", ethnocentric perceptions are formed, we instill a sense of rivalry between cultures and we validate the "other" as the enemy. Through this lens, a dualism between cultures emerges, evoking 'the Western' versus the "Muslim world" school of thought. By following this framework, we place blinders on people, this leads to creating a dichotomy. A dichotomy which categorizes people into convenient ethnic and cultural groups. According to this world view of "us" vs. "them", biases emerge, divisions between cultures are validated, and negative stereotypes of different people, due to culture, religion or ethnic background are embodied.

Current literature is suggestive that a conflict between civilizations exists; this evolution is further amplified within the European landscape, by political, mono-centric and nationalistic attitudes. Within this framework, divisions are promulgated, within the Muslim community and between Italian society and the Muslim community. Other factors are prevalent in formulating biases of the Muslim community, including the hierarchy of the Catholic Church, a general mistrust for Islam and the negative media coverage prevalent depicting Islam as a threatening phenomenon. A conflict in 
civilizations will be the latest phase, in which a conflict between Western ideals and the Islamic world continues to assume greater importance on the world stage.

One aspect of this rift between Islam and Western Europe is due to the demographic changes taking place since the late $19^{\text {th }}$ century, resulting in unprecedented immigration to Italy from the Muslim world. The growing presence of a Muslim community in Italy has created new forms of ethnic tensions and continues to generate debates on the prospects for Muslim assimilation. Toronto (2008) highlights the impact of this growing phenomenon by describing this process:

...a "marbling of civilizations and peoples" that has brought about "a new georeligious reality", as one scholar has aptly observed - generating conflict in the public arena and inducing new debates about national identity, human rights, and the nature of civil society. (p. 61)

This conflict is further amplified by a clearly defined religious debate being generated by the presence of Islam in Europe, particularly within the public domain, where conflict is exasperated by the symbolic meaning associated with the construction of Mosques, building of Minarets or by women who are marginalized by the wearing of the hijab (head scarf) or by veiling.

Perhaps the most compelling argument on the level of tolerance for Islam within the Italian framework is mentioned by Yalla Italia's chief editor in Milan, Martino Pillitteri, where he summarizes the debate between the cultural differences for Italian society and the acceptance of Islam in this manner: 
"We're separated by 10 meters, but culturally we're centuries apart," said Martino Pillitteri, Yalla Italia's chief editor. He said he saw the differences between his mission and that of Muslim conservatives as symbolic of the divide in Italy's Muslim population -“one vision driving toward the past, the other driving toward the future", he said. (As cited in Povoledo, 2009, para. 4)

My research in Italy allowed me to engage with the Muslim population in Italy and allowed me the opportunity to explore further the hypothesis presented by academics on the nuances that exist between the West and the Muslim world, specifically within the European context. My approach through interviews, on sight observation and with meeting the Muslim population, gave me the opportunity to engage first hand with the Muslim community, rather than in drawing conclusions from the hypothesis and with theories presented solely by the scholarly literature.

Through my engagement with the Muslim Youth National Conference (GMI), in December 2008, I was able to participate in focus groups with the Muslim youth who came from different regions in Italy and were representative of the demographics throughout Italy. During my focus group participation, I was able to draw the issues facing the Muslim youth, which they felt were the greatest barriers for their general acceptance or non-acceptance within Italian society. My research focused on the $1^{\text {st }}$ and $2^{\text {nd }}$ generation Muslim youth in Northern Italy and this study hopes to address the multilayered barriers facing the Muslim youth and attempts to address the negative stereotypes in which the youth are confronted with on a daily basis. My study will focus on the general attitudes in Italy confronting the Muslim youth, in their quest for 
achieving assimilation and hopes to address the root-causes impeding general acceptance among $1^{\text {st }} 2^{\text {nd }}$ and $3^{\text {rd }}$ generation Muslims residing in Italy.

Among the barriers for assimilation, neofundamentalism is attributed as a notable phenomenon experienced by $1^{\text {st }}, 2^{\text {nd }} \& 3^{\text {rd }}$ generation youth residing in Europe, this appeal by the youth to radicalization and with pursuing extremist views is a growing dilemma worthy of addressing in my study. But perhaps, one of the principle questions I wish to look into further in my thesis is notion of; "What does a Muslim really mean in relation to the Italian landscape?" My question has a much broader meaning, it's not strictly about religion, but seeks in pursuing the broader notions and prospective associated with Islam and the interaction between Muslim engagement with modern Western society, within the context of Italy. These issues are intertwined within the framework of the Muslim youth, who seek in formulating an Islamic identity within the European framework. This identity for the Muslim youth has yet to be clarified for the Italian landscape.

With referring to the Swiss ban of the Minarets, recently occurring in Switzerland by voter referendum (Nov. 2009), former Dutch Parliamentarian Ayaan Hirsi Ali (2009), explained; "What Europeans are finding out about Islam as they investigate is that it is more than just a religion. Islam offers not only a spiritual framework for dealing with such human questions as birth, death, and what ought to come after this world; it prescribes a way of life" (Hirsi Ali, 2009, para 5). 


\section{CHAPTER THREE}

\section{Methodology}

\section{Purpose of this Study}

I chose a qualitative research approach to conduct my study in order to gain a deeper understanding of the central issue: "What are the barriers for second generation Muslim assimilation into Italian society?" My strategy of inquiry will be a case study that will attempt to gauge the challenges presented by the resurgence of Islam, within Italy's spiritual geography, focusing on the social adaptation challenging the 2nd generation Muslim youth in Italy. The purpose of this study will be to examine the dynamics of second generation Muslim youth and the barriers of their integration into Northern Italian society, and to further explore to what extent the Islamic identity has influenced this process. In addition to the historical context, the subject matter of this thesis has an international context.

My research objective will be to determine the cultural attitudes, how they are impacted by Islam, as an external force, influenced by Islamophobia, thus, leading to religious conflict within Italian society. While my fundamental approach was qualitative, I choose to compile a case study, with the intent of gauging a sense of how the Islamic identity will further impact $2^{\text {nd }}$ generation Muslim populations in Italy seeking to integrate into Italian society. 


\section{Methodology Overview}

Creswell (2003), in his book "Research Design: Qualitative, Quantitative, and Mixed Methods Approaches", articulates that "qualitative research is fundamentally interpretive. This means that the researcher makes an interpretation of the data" (p. 182).

Although I acknowledge, that my own personal biography impacts my biases and values for this study, I facilitated and engaged my research with a sense of honesty and openness towards my research and sought to maintain an objective point of view. While a subjective experience of the population I choose to research was ultimately sought, a recent influx of mass immigration of Muslim populations in Italy has developed into two phenomena. The first is, how 2nd generation Muslim youth are seeking to establish their own place within Northern Italian society and seemingly needing to reconstruct their own Islamic identities. Secondly, the Europeans needing to adapt and rethink their own identities within the broader framework of the European Union as a consequence of the changes and challenges brought about by the Muslim influx. This newly developed phenomenon for European Union (EU) citizens has validated a need to integrate religious minorities and presented unique challenges for embracing multiculturalism.

The significance of this research will seek to address the dynamics of how increasingly Muslim populations in Italy will integrate into Italian society. I will examine this process more closely, and attempt to determine how newly arriving Muslims face in their efforts to establish their own cultural integration into Italy. 
Moreover, I will explore the value of Islamic identity, for 2nd generation Muslims and its relation and acceptance by mainstream Italian society.

\section{Setting and Participants}

My research will be qualitative, based on random sampling that I have conducted in Milan. A Case Study utilizing textual analysis was the best method for obtaining, evaluating and reporting such data. My research strategy of inquiry was based on; conducting interviews, participation in Muslim youth focus groups, on site observation and draws from the literature relevant to the problem presented in this study. Additionally, my methodology, draws from the literature on Islamophobia and Nationalism, this impacts the problem directly of 2nd generation Muslims seeking greater inclusion in Italian society.

The literature and discussion included in Chapters four and five of this study, extrapolates further not only from the research and data drawn through conducting interviews in Italy - but is also in alignment with the literature on Islamophobia and nationalism. That said, the literature substantiates the problem presented and adds as a backdrop to the barriers for integration of Italian Muslims. Subsequently, the literature framed in this study, strengthens my hypotheses, in which "Islamophobia" and "nationalism" are factors bearing on and influencing obstacles, that prevents Muslim integration in Italy. 
I chose four principle methods for my data collection: (1) observation while on site in Milan (2) Interviews (3) Document review and (4) Participation in focus-groups, round table discussions that were held during the Young Muslim Youth (GMI-- Giovani Mulsumani di Italia) conference in Umbria Italy (Dec. 2008). I structured my individual interviews by presenting the interviewed subjects with a "pre-drafted" questionnaire.

\section{Participants}

The targeted population for this study is the 2 nd generation Muslims who reside in the Milan area, Lombard region of Northern Italy. I chose and sought diversity in selecting the sample population for this study. The subjects for this study are second generation Muslims, whose parents are from different Muslim countries of origin and a combination of males and females, in order to maintain adequate representation for gender, within the study group. My goal with selecting the targeted population was to obtain input from a diverse group representing different Muslim nationalities.

After consultation with Professor Paolo Branca, my selection of participants was based on random sampling, my goal was to obtain a diverse representation of second generation Italian-Muslims. Although, initially I sought a larger number of participants, but later in the interest of feasibility and cost effectiveness, decided that it would be more effective to implement a stratification of my sampled participants. 
Creswell's (2003), in his book “Research Design, Qualitative, Quantitative, and Mixed Methods Approaches", provided guidance that proved to be useful with identifying the characteristics that were relevant in stratifying my sample participants, based on gender and education. The characteristics for my sample population were representative with the overall population for my study.

\section{Purpose of Research}

The purpose of this research is to analyze the dynamics and implications that impede Muslim integration within Italian society. Recent Muslim immigrants to Italy, whether first or second generations have intertwined into a cultural mix of racial, ethnic and religious groupings, generating a conflict in cultural values within Italian society.

My research will seek to explore the social, cultural and political dynamics presented by the religious visibility and growing presence of Islam, addressing the public debate generated by Muslim immigration/integration within Italian society. Research indicates that contemporary trends in immigration, suggesting demographic changes for Muslims migrating to Italy from Northern Africa are difficult to obtain or at best sketchy. My research addresses the question of how many of the Muslim immigrants actually consider themselves Muslim, and identify with Islam as the basis for their cultural origin. I will seek to define how Muslims perceive their own Islamic 
identity, whether due to cultural identity, or acknowledging their Muslim ethos, in the Italian context.

The literature indicates that approximately $33 \%$ of immigrants to Italy are from Muslim countries, according to the ISMU (Iniziative e Studi Sulla Multietnicita '). According to the latest research, the largest percentages of recent migrants to Italy are from Morocco and from the North African Continent (validated by my immigration conference attendance in Milan, Italy hosted by the ISMU - April 2008).

\section{Research Questions}

My research questions are inspired by the many challenges that recent migrants from Muslim countries face with the process of adapting to Italian society, some of which are related to gender, and to religious identity. These factors impact the process of integration, which is also further influenced by the media. The media, which often presents "Islam" in a negative light, contributes in complicating integration and by conveying attitudes of mistrust of Islam in Italian society. Many Muslims that have migrated to Italy, tend to embrace democratic values while seeking to retain their Islamic identities, they rely on Islamic clerics, community leaders and Islamic principles to guide their daily lives. It is this awareness of these conditions which inform the following research questions: 
- What obstacles and challenges face $2^{\text {nd }}$ generation Italian Muslims in regard to achieving full integration in Italian society?

- Will the reframing of $2^{\text {nd }}$ generation Muslim identities and their compliance to Islamic principles conflict with the generally tolerant Italian society?

- Is the resurgence of Islam in Italy, the practice of Islamic faith and ideology, truly compatible with secularism, democracy and with European values?

- How many of the $2^{\text {nd }}$ generation Italian Muslim young adults actually consider themselves Muslim and define themselves within the context of Islamic identity?

\section{Hypotheses for this study}

The fundamental motivation for this study is, the conviction that structural challenges exist and remain prevalent within Italian society that create barriers for second generation Muslims while pursuing their quest for achieving equal status within Italian society. Elements of these challenges are:

- The privileged position of the Catholic Church within the Italian State

- Citizenship limitations for $2^{\text {nd }}$ generation Muslim youth

- The need to obtain permission from regional political authorities in order to build Mosques in Italy 
Multi-faceted challenges remain prevalent and confront Muslims in Northern Italy as they seek to achieve greater public status and equal rights within mainstream Italian society. My research focuses on the cultural adaptation of the Muslim community in Northern Italy, exploring the dynamics that obstruct their efforts towards achieving integration.

Based on the literature examined and my experiences in Italy, I have developed the following hypotheses. The rise of "Islamophobia" in Europe has a bearing on the barriers affecting $2^{\text {nd }}$ generation Italian-Muslim integration. Secondly, the resurgence of "nationalism" within a segment of Italian mainstream opinion has an impact on the obstacles to integrating $2^{\text {nd }}$ generation Muslims into Italian society.

Citizenship also impacts the process for achieving greater inclusion in Italian society for Italian-Muslims. Citizenship ${ }^{10}$ for $2^{\text {nd }}$ generation Muslims in Italy under Italian law is not an automatic process upon birth. The interviewees in this study had dual citizenship. The citizenship of their parents country of origin and were granted Italian citizenship upon reaching their $18^{\text {th }}$ birthday. If a $1^{\text {st }}$ or $2^{\text {nd }}$ generation Muslim chooses not to apply for Italian citizenship, they must apply for a residency visa, based on their status in Italy. Long term residency status is given, but it is based on your general status for residing in Italy. Typically, long term residency is granted for

\footnotetext{
${ }^{10}$ Under Italian immigration laws, citizenship at birth is not automatically granted for a person whose parents are foreigners. A person may apply for Italian citizenship upon reaching their eighteenth birthday. Once Italian citizenship is granted, a person of foreign parents will hold dual-citizenship.
} 
employment, family members residing in Italy and students who are pursuing higher education.

Specific factors that impede Muslim integration are hypothesized to be the following:

1) The diversity and division found within the Muslim community, amplified by a general mistrust of Islam in mainstream Italian society.

2) The negative stereotyping by Italian media coverage that induces the broader notion of Islamophobia, presenting a biased and inaccurate illustration of Muslims in general, leads to a representation of Islam in a negative light.

3) The ambiguity conveyed by the Roman Catholic Church hierarchy and its reluctance to validate Islam and other religious minorities.

4) Italian nationalism amplified by political movements and ideology, like the Northern Italian League, where they convey a universal narrative that is "antiforeigner”, “anti-Muslim”, denying Muslims any attempt in gaining equal rights within Italian society and obstructs Muslim integration.

5) The current implementation of the concept of Multiculturalism may not be adequate to address the conflict and challenges facing Muslim integration. This is particularly the case with citizenship limitations faced by $2^{\text {nd }}$ generation Muslims.

\section{Questionnaire}


The questionnaire is structured in three parts. Part one of the questionnaire was designed based on a suggestion from my research Professor Paolo Branca, from Catholic University in Milan and is intended as a "demographic indicator", specifying "parents' country of origin. Below is a sample of the three parts addressing questions related to "identity". The questionnaire is designed to gauge "cultural identity" and "ethnic origin" (Questionnaire is included in Appendix A of this study):

1) Part I - Personal data. The subject specifies his or her, ethnic background, parent's country of origin and social status.

2) Part II - An open ended question is posed--"What is the significance of Islam for you?"--followed by statements aimed at gauging how the subjects self-categorized their identity. Here they are able to indicate how strongly each statement reflects their own attitudes.

3) Part III - Two questions are presented. This section seeks to discern the subject's attitudes towards integration into Italian society. The first question asks an open ended question on how they perceive their identity, giving examples of possible identities. (1) "How do you perceive your identity?" This is followed by an example listing: "European - Muslim - Italian". The second question aims at eliciting their own thoughts and experiences as Italian-Muslims living in Italy.

(2) "How has Islam impacted your public life, while living in Italy?" 
My research design is to use this questionnaire to present several open ended questions related to identity, religion and cultural adaptation to $2^{\text {nd }}$ generation Italian Muslims. Additionally, the data collected from the questionnaires is analyzed to find common themes and understandings related to cultural identity. My questionnaire was designed to allow the researcher to gauge some of the barriers and challenges that second generation Italian-Muslims face impeding integration.

Consequently, my study evolved into an exploration attempting to measure complex ideas on "religious identity", "belonging", and "culture of origin", seeking to frame the context of the Muslim population in Northern Italy as a sub-culture to the dominant culture. Spena (2010), in her recent chapter "Muslims in Italy: Models of interaction and new citizenship", gives us an example by illustrating the importance of defining identity and its relationship to culture:

The most common method of religious classification for migrants is to refer exclusively to the official or majority religion in a migrant's country of origin. In other words, it is based on national and not on ethnic and/or confessional criteria, which leads to a degree of ambiguity in the interpretation of data if one intends to construct a typology around religious or cultural parameters (as cited in Triandafyllidou, 2010, p. 161).

\section{Research Design Validity}

The validity of this design will attempt to gauge the cultural acceptance of my research subjects within Northern Italian society. This study utilizes a case study strategy of inquiry. My research design was structured as a measuring tool for examining consistency with responses and to determine any emerging patterns. 
Creswell (2003) went so far as to suggest, "Moreover, when qualitative researchers use a theoretical lens, they can form interpretations that call for action agendas for reform and change" (p. 195). Consequently, "interpretation in qualitative research can take many forms, be adapted from different types of designs, and be flexible to convey personal, research-based and action meanings" (p. 195).

While contemplating my design, I structured my research with the intent of encapsulating external validity, by cross-referencing my findings and data with my literature. I randomly selected a sample from my chosen population, second generation Muslims residing in Italy, by presenting questionnaires and interviews that are structured to determine the importance of religious cultural identity. When developing my research design, I found that a case study utilizing textual analysis was the best method for retrieving, analyzing and reporting such data. Additionally, questions were designed to gauge a participant's perceived country of national origin, cultural ties to country of family origin and assist with determining value placed on religious identity.

\section{Data collection - The Instrument}

The data collection instrument consisted of four open-ended questions (See Appendix A). I specifically designed my instrumentation, a questionnaire in collaboration with Professor Paolo Branca. Permission for utilizing my instrumentation had been granted by the Human Subjects Research Review Committee (HSRRC) before I began my interviews in Milan, Italy. 
The instrument was a result of a synthesis between questions presented in the questionnaire, interviews, direct observation and my participation in the Muslim youth focus groups -held at the GMI Conference in Umbria (December 2008), where factors impeding assimilation where discussed among my focus group members. During the conference, we broke down into small groups of ten people and I participated in a structured open round table discussion. We had a designated group leader who facilitated our discussion. I was fortunate to have conducted both interviews and engaged in the GMI four day Conference. My participation in the Muslim Youth focus groups, allowed me as the researcher to interact in a "first-hand experience with the participants" at the site of my area of study. Having conducted the research in a natural setting, proved to be useful in exploring topics that may have been "somewhat uncomfortable" for participants to discuss, otherwise.

\section{Data Analysis and interpretation}

According to Creswell (2003), "Discussion of the plan for analyzing the data might have several components. The process of data analysis involves making sense out of text and image data" (p. 190). After carefully analyzing questionnaires and interview notes, I noticed common themes began to arise that coincided with my literature presented in my study. I recognized the need to tailor my data analysis in line with the type of research design. As noted by Creswell (2003), "Researchers need to tailor the data analysis beyond the more generic approaches to specific types of qualitative research strategies" (see also Creswell, 1998). 
After reading through my journal notes and the results of the questionnaires, I sought to reflect upon common trends and themes, by posing the following three questions: (1) "What general ideas are participants saying?" (2) "What is the tone of their ideas?" (3) "What is the general impression of the overall depth, credibility and use of the information gathered?"

My aim for analyzing the data was to obtain a general sense of the information, within the framework of ethnography and to reflect upon the overall meaning. I analyzed the data to gain insight as to what the trends and patterns are related to cultural identity. Subsequently, I attempted to analyze this data from an objective point of view. Through questionnaires, observations and interviews, I sought to determine what the common trends were related to religious and cultural diversity from the participants. I noted observations and experiences from my research that are subjective in nature and I attempted to gain knowledge on "the points of view held by the subjects". Due to confidentiality for the subjects participating in this study, I selected emerging themes and patterns from my data and generated a coding process to identify common themes from the data. Additionally, I coded my data from my participants with the goal of establishing common themes and patterns that will prove useful with establishing connectivity to my overall theory.

\section{Limitations}

After careful analysis of my interview notes and from the results of questionnaires, themes began to arise that were consistent with the literature presented 
for my study. I found that the limitations that I encountered for my research were consistent for Qualitative data collection. For the most part, the advantages for my chosen research design outweighed the limitations. Subsequently, I found that my presence during the interviews may have conveyed a sense of awkwardness from the subjects' point of view. As a non-Muslim, during the interview process, I found that my presence could have easily been interpreted as being intrusive. 


\section{Chapter Four}

\section{Defining Islamophobia}

\section{Influence of Historical attitudes leading to Islamophobia}

Muslims have been present in Europe since the early periods of Islam, dating back to the seventh century A.D. Europe, historically has had a continuous interaction with the Muslim community and Islam since the Moorish civilization in the Iberian Peninsula. Muslim and European interaction were also prevalent during periods of religious conflict, particularly during the Crusades. European interaction with Muslims dates back centuries. European involvement with the Muslim world increased enormously during the era of European Colonialism and Imperialism. In the case of Italy, this was primarily within the Northern African Continent and continued up through the middle of the twentieth century.

During the post World War II era, Muslims began migrating to Europe from the developing world and former colonies, as they sought better economic opportunities. More recently, as a consequence of international wars, occurring in places like the Balkans and in Somalia, this civil and political unrest that Muslims were experiencing in their homelands resulted in a new and expanding wave of migrants for the European landscape. The expanding populations of primarily migrant workers and asylum seekers generated new social and political challenges for Europe, formulating into modern day anti-Muslim sentiments. Muslim migrants residing in Europe were marginalized from predominantly European society. 
Erdenir (2010) illustrates:

Europeans started to discover Muslims through events that had an international impact, such as the Iranian Revolution, the Salman Rushdie affairs in the United Kingdom, the headscarf affair in France, the 9/11 attacks, subsequent terrorist attacks in Madrid and London, the Danish cartoons crisis, and so forth. Through these developments the passive image of Muslims transformed into one that was aggressive (p. 27).

Historically, the relationship between Muslim minorities and national majorities in Europe has been problematic. This relationship has been steadily eroded since the attacks of $9 / 11$ and by the aftermath following $9 / 11$, primarily, the military engagement that followed generating conflict in multiple Muslim countries. Over the past decade, perceptions of Muslims and Islam, by Italians and for Europeans, have been greatly amplified by the emerging negative stereotypes and by influencing Italian public opinion on Muslims and by perpetuating a general attitude of fear and avoidance.

A post 9/11 Europe, has morphed into renewed fears of Islam, generating a modern day renewal known as "Islamophobia". The term "Islamophobia" carries a more profound meaning then simply conveying fear, it also exemplifies multiple negative concepts; religious discrimination, intolerance for the other, racism and "antiIslamism". Erdenir (2010) notes, "Perceptions by host societies of Muslim immigrants, which have not been free of fears and prejudices, have played a significant role in this problematic interaction" (p. 27). 


\section{Definition of Islamophobia, does Nationalism play a role?}

How do we define Islamophobia? According to Erdenir, the term was first used by the Orientalist Etienne Dinet during the twentieth century in 1922, the term became much more prevalent in the 1990's, “especially after its use in the much cited report "Islamophobia: A challenge for Us All” by British NGO, the Runnymed Trust"(Erdenir, 2010, p. 28). Moreover, Sheridan and Gillett state, "Islamophobia could simply be defined as a "modern epidemic of an age-old prejudice towards and fear of Islam" (as cited in Erdenir, 2010, p. 28). While the term Islamophobia may be representative of age old prejudices towards Islam, it would be misleading and rather naïve to attribute hostilities towards Muslims to religious conflicts dating back to the eleventh century, or by drawing parallels to the Muslim invasions of parts of Europe during the Middle Ages.

Past conflicts and invasions by Muslim armies are not foremost on the minds of Europeans today. But, contemporary Islamophobia and anti-Muslim sentiments for Europe and in Italy are. The phobia today of Islam, remains much more complex and represents a collage of multi-layered sociological and cultural differences; they are further influenced by political narratives established by the far right, most notably ( $\mathrm{La}$ Lega Nord) "the Italian Northern League". The issues presented by the Northern Italian League, by promoting a xenophobic nationalistic campaign, directly impact the Italian population. The ultra-conservative views of the Italian Lega Nord, have successfully organized a campaign against the Muslims, where they have created a scapegoat in denouncing Muslims and by demonizing Islam. Toronto (2008) further pointed out the 
nationalistic narrative amplified by the Lega Nord, "Reference is often made to a distinction between "us" and "them", and images equating Islam to terrorism and abuse of women frequently appear in the party's publicity" (p. 69). This ultra-right propaganda is designed to designate Islam as an enemy for the Italian State and raises anti-Muslim sentiments. Within the context of the nationalist narrative, this ideology demands absolute and unquestionable loyalty to the State and emanates ethnocentric ideals.

During the past decade, respected scholars, including Huntington, have attributed anti-Muslim sentiments and Western misconceptions of Islam to a broader concept, framing the existing animosity as "a Clash of Civilizations", meaning a clash of ideals between "Islam and the West".

Edenir (2010) eloquently argues:

The problematic situation Muslims face with regard to religious education, dietary laws, clothing and observance of religious ceremonies seems to be related to their religion, but they are in reality, social issues that end up having implications in a secular system. In other words, the clash is not between civilizations as Huntington had claimed, but more between lifestyles. The aim should be to figure out the real and material causes at the root of the conflict ( $\mathrm{p}$. 28).

As we examine the historical influences leading to this growing phenomenon of anti-Muslim sentiments, Toronto (2008) argues "The harsh reality for the Islamic community is that the image of Muslims remains negative and feelings of Islamophobia run deep in Italian society" (p. 68). In fact, Europeans are not afraid of the religious connotation that Islam represents. Italian sociologist, Allievi attributes modern day 
Islamophobia as a phenomenon that is rooted into a historical context. He proposed that this could be connected to the long history of raids along the coast of Italy carried out by Saracens (Muslim pirates) that left an indelible impression of fear in the "collective unconscious" of Italians. This relationship for Europeans may be further exacerbated by the mere public presence that Islam conveys. Additionally, Erdenir (2010) went so far as to suggest, "Islam might be disagreeable in a secular Europe where people do not have sympathy for those who openly assert their faith in the public sphere" (p. 29).

In addition to the historical context, Toronto (2008) asserts:

This long-standing association of Muslims with danger and terror in the Italian psyche was, of course, only confirmed and deepened by the events of 9/11. Adding to this image of Muslims as aliens is the fact that relatively few Muslims are Italian citizens and the strong perception (with some grounding in fact) that most Muslims retain strong loyalties and cultural ties to foreign countries (p. 69).

The majority of Europeans are not familiar with the internal dynamics of Islam; they are not living in fear of accommodation of Sharia law or Islamic jurisprudence (figh), within EU constitutions. The controversial debate over the status of women is not widely known to mainstream Europe, including Italy. The various interpretations of the Quran, including how the conformity of Sharia may impact Muslim lifestyles are not widely known. Consequently, many misconceptions arise related to Muslim women and their chosen dress in public, particularly with the wearing of the headscarf, this protocol derives from Muslim cultural traditions, and less from established Islamic laws. There is no pressure for Italian society in converting to Islam and discussions do not address revelations of the Quran. Therefore, the principle reasons for the fear or phobia that 
Europeans have are found elsewhere, it is a broader phenomenon. In part, the fear that European societies emulate derives from a phobia influenced by rising Islamic fundamentalist movements in the Islamic world and by a perceived growing threat of fundamentalist ideology, capable of influencing Europe. Erdenir argues that, "The fundamentalists, in turn, justify their actions by invoking Islam. Yet in reality the basis of their actions is not an eternal Islamic code.” (p. 29).

A deeper examination reveals that the root-causes in defining the true meaning of Islamophobia experienced by the Europeans go beyond religion; they are multidimensional and cannot be solely based on a lack of understanding of Islamic teachings. Islamophobia encompasses other social phenomena outside the realm of religiosity, including and related to; marginalized communities, underprivileged societies at home, economic disparities and repression by a political structure. Erdenir (2010) further illustrates:

It would be misleading to identify Islam as the cause of the phobia and therefore the term "Islamophobia" alone would be insufficient since it assumes the dominance of religious discrimination over other forms of discrimination that may in many cases be more relevant (p. 29).

Another factor contributing to the fear of Islam is the concept of Muslimophobia, this term does not represent historical theological conflicts, but is a byproduct from a modern day expression deriving from a secular and modern form of anti-Muslim sentiment. Erdenir, attributes this distinction validating Muslimophobia as a European phenomenon, related to European perceptions of Muslims, including second generation Muslims who are non European citizens. Erdenir (2010) distinguishes the conceptual 
differences in this way, "Even though there is fluidity between the two concepts, Muslimophobia is distinct from Islamophobia in the sense that the former targets Muslims as citizens or residents of European Islam but the Muslims who are in the spotlight" (p. 29).

Additionally, in reflecting how the Islamic world is attempting to find itself within the European context, Erdenir explains that Muslimophobia is a sort of "new racism" which targets cultures, lifestyles and physical appearance of Muslims (Erdenir, 2010, p. 29). Secularization represents separation between religious institutions and the State, although for Italy the Vatican maintains a central role in the societal level, the general notion of secularization is widely accepted.

Erdenir highlights how, religiosity remains the main identity marker among Muslim immigrants in a somehow secularized Europe. This variable in religious identity among Muslims contributes to the perceptions being drawn that represent Muslimophobia and impacts the process for 2nd generation Italians who are seeking equal footing within Italian society. Moreover, the anti-Muslim sentiment represented in Italy is further exacerbated by the nature of Islam, which is inherently public. Consequently, Erdenir (2010) acknowledges, “At present, the gradual recognition of Muslims and the institutionalization of Islam are happening along with discrimination and hostility. But Europe has the cultural background and social mechanisms which enable the accommodation of different worldviews and values" (p. 40). 
In conclusion, the essence of Islamophobia as a growing phenomenon has negative implications for either $1^{\text {st }}, 2^{\text {nd }}$ or $3^{\text {rd }}$ generation Muslims residing in Italy. Among these we find that, the aftermath of 9/11 and the consequent inundation of media coverage focusing primarily on the negative aspects of Islam--where Islamic fundamentalism and the more radical militant ideologies are being continuously broadcasted--have created obstacles for the $2^{\text {nd }}$ generation Italian Muslims who seek to establish greater inclusion within Italian society. The negative connotations of Islam, as we find in the growing trend of Islamophobia, validate my hypothesis. Islamophobia has led to a biased and inaccurate representation of Muslims in general. Moreover, the negative attitudes framing a insular viewpoint of Islam, commonly found within the mainstream Italian context, directly contradicts the narrative that the concept of Multiculturalism seeks to establish. According to Erdenir (2010), "The terms Islamophobia and Muslimophobia do not target legitimate criticisms such as the denouncement of human rights violations in certain Islamic countries. They are used to cover any ungrounded fear and prejudice against Muslims, their faith, and practices" ( $p$. $30)$.

Subsequently, Hellyer (2006) asserts, "The dynamics of immigration, EU integration and globalisation [sic] have raised new questions surrounding what is meant by the "European identity", and the debate is still very much open" (p. 348). Thus, the need for greater integration of $2^{\text {nd }}$ generation Muslims and greater inclusiveness within Italian society overall arises. Perhaps Multiculturalism remains a suitable framework for 
addressing the process of Muslim integration in Italy, as they seek new ways to achieve greater inclusion. Although, given the current disparity between the Muslim community and mainstream Italian society, it is relevant to point out that my hypothesis addressing the current conceptualization of Multiculturalism in the context of the European nation States, may be outdated and inadequate in addressing the values of Muslims in Italy. This calls for new thinking by the Italian state, as they seek to address and overcome the challenges facing the Muslim population, who are seeking to establish greater equality. 


\section{CHAPTER FIVE}

"Every civilization that has come through history has had some sort of concept of citizenship; it may not have been described as such, but one of the prerequisites for a civilization is to create some sort of a common identity to base it upon. Without such a common identity, there is no community and no society, which results in lack of solidity and, eventually, chaos" (Hellyer, 2006, p. 329).

\section{The concept of Multiculturalism}

Throughout modern history, the nationalistic extremes as experienced in Germany with the rise of Nazism and in the Balkans as ethnic conflict emerged in the form of "ethnic cleansing", the supreme notion of placing the state, in a sacrilegious pedestal have diminished. To this end, these extreme forms of establishing a monoethnic narrative and by placing the nation state as a sacred unified ethnic-nationalistic establishment have become and obsolete model for structuring societies. European societies have become more diverse, greater awareness of religious groupings have been articulated, generating debates on developing imaginative models for restructuring societies which are more inclusive towards religious minorities. Hellyer (2006) argues, this modern day form of inclusion, has led Europeans to develop new frameworks of thinking, resulting in the implementation of Multiculturalism.

In his study, Hellyer found:

Multiculturalism is, to date, the most developed framework in European societies to manage this diversity, and the current trend is heading firmly in that rather broad traditions: the idea of a narrow and forced assimilation process is no longer entertained as a viable option in the EU (Hellyer, 2006, p. 345). 
By managing this cultural diversity, the framework of Multiculturalism addresses the challenges faced by the European Union, with having nations composed of diverse religious identities, and cultural minorities. In his article, Hellyer further analyzes how the challenges posed to academics, NGO's and other entities are being dealt with, by integrating and formulating protective policies within the EU that allow the integration of ethnic and cultural minorities. The EU has emphasized the development of imaginative models, in which the state would manage effectively the cultural, religious and ethnic diversities. Rising Muslim populations across Europe have created a variety of cultural issues that the EU must address. These include issues of universal values and gender subjugation where Muslim cultural practices are at odds with current European behavioral standards. Many cultural and religious based issues are being evaluated by the EU member states at this time, with particular emphasis on France and Germany; from the wearing of the headscarf (hijab), to the compliance of Muslim laws, to the conformity in public schools. The issues that have confronted the European community with integrating ethnic minorities are being discussed in relation to other religious groupings, particularly within the context of the European Muslims.

Will we find Muslim communities residing in Europe, further challenging European mainstream cultural values in the $21^{\text {st }}$ century? Or will Europeans and EU integration view Muslim communities as legitimate minority subcultures, having perspectival differences that will hinder integration within the public domain of European Society? Bearing in mind the challenges faced by the notion of assimilation, it 
becomes clear that the Muslim presence in the EU has an added dimension, where the process for integration must find a medium to accommodate both genders, in a fair and equitable way. The principle debates in the EU, including Italy, have been centered on primarily the Muslim population and the particular challenges that EU society faces with drafting a suitable process for integration. Hellyer (2006) stated that:

The fact that Islam has a long running history in Europe, with many European identities having been formed in contradistinction to Islam, makes the challenge even more involved. Multiculturalism is, to date, the most developed framework in European societies to manage this diversity, and the current trend is heading firmly in that rather broad tradition: the idea of a narrow and forced assimilation process is no longer entertained as a viable option in the EU (p. 345).

\section{Multiculturalism: a recent Historical Background}

According to Hellyer (2006), "it is difficult to find a country in the world that has absolute uniformity in terms of religious identity" (p. 329). He further explained by inciting, how examples of ethnic and religious diversity exists today among countries in various regions, such as; the Jewish state, the heartlands of Islam, the Catholic states of southern and western Europe. Religious diversity within states historically has existed for centuries. A distinction is made noting how some countries throughout history have accepted and lived harmoniously within religiously diverse societies. Although, the thirteenth century Ottoman Empire (1299-1922) was composed of predominantly Muslim countries, religious diversity was integrated and ethnic minorities lived without fear of persecution. 


\section{The Debate of Multiculturalism}

In Europe, the Ottoman's and the Austro-Hungarian empires had a system of differentiation that was based on religion. The systems of governance were somewhat accommodating to minority religious groups. The citizens of the Ottoman Empire were given the choice to follow their religious laws, or the laws of the Ottoman state. In other countries, where religious diversity was more restrictive and not viewed favorably, religious minority groups were persecuted. During the period of modernity $\left(18^{\text {th }}, 19\right.$ th Centuries), with the creation of the nation-state, countries and borders were formulated, new nationalistic ideals emerged. Thus, Hellyer (2006) notes how with the birth of the nation-state, consequently, nations were structured around the majority groupings (either religiously or culturally); nations would assume the identities of the majority, culturally and nationally.

Mayall, gives an example of how this shift in cultural groupings developed during the early $20^{\text {th }}$ century:

after 1918, the nation theoretically was succeeded by the state, but that minorities within those states were "left out in the cold"; the majority and the minority assumed that the state had to be based on a nation, which generally had a single religion, and the obvious conclusion was that the majority's nation would be it (as cited in Hellyer, 2006, 329).

Given the historical occurrences from Nazism, ethnic-cleansing, migration patterns, the twentieth century ideals of ethno-centric nationalism, and the notion of the 
state, resulted with nationalism leading Europe to World War II. With the formulation of a transnational EC, the state had now assumed a role of lesser importance. Greater emphasis was placed on establishing trans-national engagement. European attitudes and political culture shifted, recognizing the need to emphasize and respect the rights of ethnic minorities, further acknowledging a broader multicultural society resulted. Ethno-cultural minorities, sought to have their lifestyles and cultural values recognized. Europe's focus shifted assuming a new priority, by emphasizing the protection of religious and ethnic minorities. Thus, the integration of diverse religious minorities has become a central focus of much greater importance.

Just as Muslim juridical scholars and religious theorists are attempting to analyze the impact of modernity on Islamic jurisprudence, European political philosophers acknowledge that the traditional understanding of identity and belonging have been altered in Europe, hence, recognizing the need for creating a new set of norms. Additionally, Hellyer (2006) stresses, "the dynamics of immigration, EU integration and globalization have raised new questions surrounding what is meant by the 'European identity', and the debate is still very much open (Hellyer, 2006).

\section{Muslim Identity Related to Multiculturalism}

Conflict, cultural traditions and diverse religions, have been a part of our society for centuries. Conceptualizing the differences will help us attain a greater understanding for resolving conflict in the future. Islam (as global universal faith) in itself is not a culture, thus, since Islam as a religious faith did spread throughout the world, the 
Muslim communities with Arabic origins did not. Hellyer (2006) went so far as suggesting, what did occur throughout the Muslim communities, “...was a process by which cultures were filtered or adjusted but never entirely banished by Islam (Hellyer, 2006). Therefore, the concept of a universal Islamic identity is somewhat problematic. The mission of the Prophet was to spread Islam and Islamic values, not the common identities that were formed among Muslims; a collective identity resulted from personal adaptations of segments of Muslim traditions and values, which resulted in establishing common Muslim identities. Martin Baumann found:

Most discussions about multiculturalism focus on 'ethnicity'. As a side effect, the recognition of religion and religious identity is marginalized or not considered, yet research show that religion 'still' plays a significant role in groups' relations among each other and the society at large (as cited by Hellyer, 2006, 336).

There is a mutual consensus among European political thinkers emphasizing diversity; they recognize the need that there should be integration and respect for diversity within the European society. Establishing integration of European society will be based on determining under what parameters common citizenship will assume. The importance of establishing the common citizenship framework for Europe, will formulate how European society will choose to integrate ethnic and Muslim communities in the future, forming cultural cohesiveness for modern European society well into the $21^{\text {st }}$ century.

\section{Multiculturalism vs. the Dominant Culture}


Bhikhu Parekh in a recent study suggested a possible solution, by presenting three variations of cultural diversity and their relationship to the dominant society. Parekh categorizes these three groups as:

1) those who 'broadly share their society's dominant system of meaning and values and seek to carve within it space for their divergent lifestyles

2) those who follow 'perspectival diversity', whereby they differ with the mainstream on how the dominant culture should be reconstituted

3) those who establish 'Well organized communities' entertaining and living by their own different systems of beliefs and practices' (as cited by Hellyer, 2006, pp. 336-337).

The challenges faced by accommodating the cultural aspects of Muslims residing in Europe are typical for subcultures with perspectival differences from mainstream society. These differences are not limited to lifestyles alone, but encompass cultural diversity related to the subjugation of gender. As an example, the wearing of the headscarf (hijab) by Muslim women in France is seen as a form of female subjugation, thus, opposing French universal values. The headscarf debate, representing a form of oppression for women, is not unique to France, but has been the center of controversy in Germany and Turkey, and tends to reappear among other EU states. France's government advised to ban the wearing of the headscarf, hoping to promote and ease integration among Muslim women, within French society. For Muslim women residing in France and within European society, regardless if they choose to display their religious identity by wearing the hijab, their religious identity which is symbolized by the wearing of the headscarf, should be acknowledged. They 
have shown a willingness to interact with mainstream society; i.e. while in public service, education or within the public domain.

The ban on wearing the headscarf in France and Germany is controversial and open to debate. Hellyer (2006) notes, "Indeed, one of the greatest arguments against the ban is that it will create a de jure exclusion of devout Muslim women from mainstream life; a measure which is discriminatory on the basis of religion and of sex, hindering integration, as opposed to aiding it" (Hellyer, 2006, 341). This is a battle suggesting interpretations of cultural aspects that are deemed universal by French society, and how they differ from Muslim women wanting to display their identity openly and within the public domain.

\section{Multiculturalism and Redefining European Society}

Europe faces many challenges with integrating Muslim communities and ethnic minorities into mainstream European society. Both European political philosophers and Muslim legal theorists recognize that there is a need for a new paradigm that places greater emphasis on "religious pluralism" compared to the traditional understanding of identity and belonging in European society. Affecting the changing circumstances are the dynamics presented by multiculturalism, immigration, EU integration and globalization, all of which, bring about a new cultural dimension that EU leaders will need to address. The dynamics of immigration and cultural diversity challenge the meaning of what is meant by "European Identity" and this debate is likely to continue in the future. European leaders have acknowledged by consensus the acceptance and 
respect for diversity within European society. Determining the component needed to formulate a cohesive society for Europe; allowing integration of Muslim communities while preserving European values, will remain a challenge for the European community. As noted by Hellyer (2006), "This article considered the application of a form of liberal pluralism, whereby a useful interpretation of multiculturalism was used to uphold the principle of respect for diversity, as well as a concern for a sustainable common citizenship, necessary for the cohesiveness of modern European societies"(p. 348).

The progress that European society has made with applying "citizen-based polity with the EU", as European citizens, but also as citizens of individual member states, allows the framework for Muslim integration within European society. The future of the EU will be dependent on allowing proper representation of Muslim minorities, greater tolerance for diversity and with the integration of religious minorities. As the EU seeks to draft the proper framework for integrating the Muslim communities within the social mainstream successfully. 


\section{CHAPTER SIX}

Christopher Allen wrote, "Whether the hyper realistic "other" of urgent history is controlled or feared, remains to be seen, but what is for sure, is that in the foreseeable future, Europe's "other" will remain undoubtedly Muslim"(as cited in Hellyer, 2006).

\section{Discussion}

\section{The concern of Islam-Models of Integration for Second Generation Muslims}

There are two primary dimensions of concern related to the increasing tensions that the presence of Islam has generated for Europe during the past decade. State and international institutions play a decisive role in addressing these challenges. That said, any future cohesiveness between the Muslim population and Italian society are dependent on charting future policies that would lead to generating awareness on the role of Islam and improve the process of assimilation.

Sara Silvestri's (2010) characterization of the two dimensions influencing the role of the state and impacting the public perception on Islam are categorized as "Internally" and "Externally". "Internally", refers to the challenges that the Muslim minority population face nationally, within the context of the nation state. "Externally", presents a broader outlook, where the role of "transnational political actors" outside the state and how they remain connected to the Muslim population, within the context of Islam. Her definition by distinguishing the role of the state from a broader perspective presented by international institutions provides a framework for understanding the complexity of the situation. Silvestri, argues that "Externally", European foreign policy 
is concerned with the future of relations with the so-called Muslim world and with transnational political actors that are connected to Islam" (Silvestri, 2010, p. 45). Moreover, within this framework of understanding, each of the two dimensions are characterized by overlapping interests and by a more specific set of closely related concerns. The data collected for this study, suggest that this lack of framework of understanding addressing these issues were of foremost concern to the second generation Muslims who I met with. The issues that were most mentioned during my round table discussions were directly related to "anti-discrimination" and "greater freedom of religion", which includes greater flexibility by the State for permitting the construction of more Mosques in various Italian cities. According to Silvestri (2010):

Internally, inside the borders of the European Union (EU) member states, awareness of ethnic and religious pluralism is growing. Scholars and policymakers have recognized that European legal and political systems should be adjusted in order fully to implement the principles of equality, antidiscrimination and freedom of religion, and better to govern ever more diverse and interconnected societies (p.45).

Additionally, Islam carries a universal message, this message impacts directly the Muslim community and poses challenges not only for European actors, but for the Muslim population. Islam as a influential and external force, represents competing interests with Europe, these ideological forces within the broader Islamic community, represent greater challenges for second generation Muslims, by infringing on their efforts in achieving equal footing within Italy's religious landscape.

It has also been gradually acknowledged that a transnational religion with a strong universal message, as found in Islam, is not just increasingly visible and assertive 
in Europe, but has obviously becomes an important "feature" of Europe, since large numbers of people of Muslim faith have settled permanently in Europe and are in fact, or at least aspire to become, "European citizens" (Silvestri, 2010, p. 46).

In order to improve the institutionalization of Islam, across a broader spectrum within Europe, Silvestri (2010) noted that, "Muslim communities are implicitly expected to adopt and adapt to the existing pattern of relations between the state and ethnic and religious communities in order to engage with the social and political context of where they live" (Silvestri, 2010, p. 49).

Silvestri, recently sought to gain a better understanding of the existing patterns of relations in place, by drawing a comparison between Muslim institutions and their effectiveness in reaching their respective communities within the European framework. Silvestri (2010) wrote, "I took into account the perspectives, strategies and narratives of a selection of European governments and related them with those of a selection of Muslim associations and networks that operate in European countries" (as cited in Spena, 2010, p. 49). The results found coincided with my research in Italy, that much improvement is needed in structuring better relations between ethnic and religious communities, with that of the state. In fact, many second generation Muslims who I engaged with during my visits to Italy, sought greater inclusion and more interaction within European institutions, including at the grass roots level. By engaging and promoting their cause, through magazines and publications, like "Yalla Italia" and the online publication of "Vita" magazine, the Muslim youth are not only bridging gaps and 
creating greater awareness in Italy to their cause, but they are also sharing their experiences with other Muslims who are seeking greater representation.

Silvestri (2010) went so far as to suggest:

Muslim councils are a relatively new invention, created with the expectation that they will constitute official interlocutors available for consultation and capable of representing the internal diversity of the Muslim communities that exist in European states, thereby acting as bridges between the grass-roots level and the state (Silvestri, 2010, p. 49).

There is a mutual consensus among European political thinkers emphasizing diversity; consequently they recognize the need that there should be integration and respect for diversity within European society. Establishing integration of European society will be based on determining under what parameters common citizenship will assume. The importance of establishing the common citizenship framework for Europe, will formulate how European society will choose to integrate ethnic and Muslim communities in the near future, determine future coexistence and impact forming cultural cohesiveness for modern European society well into the $21^{\text {st }}$ century. That said, within the framework of establishing citizenship for Muslims, either $1^{\text {st }}$ or $2^{\text {nd }}$ generation, the questions of lifestyle, cultural coexistence, multiculturalism and inclusion within Italian mainstream society are raised, presenting multi-layered challenges from a nationality perspective. Consequently, the need arises for granting greater recognition of minority religious groups, this process could be achieved by acknowledging the urgency in designing ways by state agencies for promoting and incorporating the establishment of Muslim representative institutions. 


\section{Muslims in Italy, the role of citizenship}

The process of integration and for the settlement of new citizens in Italy is complex and impacts directly pre-existing attitudes formulated by Italians towards second generation Muslims. The dynamic of citizenship within the Italian context is fundamentally important. Citizenship holds overlapping concepts and presents conflicting ideas as to implementing effective measures that are representative of Muslim values and promote their cause. Closely tied to citizenship are the cultural barriers that prevent Muslims from gaining broader recognition within Italian society.

Contradictions arise with respect to establishing equal status, various tensions and general attitudes for exclusion are brought to surface. According to Silvestri (2010), “...a structural problem comes into play when we talk of Muslim engagement and representation within European states and societies; that is, the idea that Islam should 'fit in' with the criteria that regulate relations with the dominant faith group" (p. 49). Subsequently, Muslim communities are expected to adapt to existing patterns established by the state, structured on the dominant culture, in order to engage with social and political representation. This process of engagement for the Muslim minority community, assumes even greater challenges in Italy, state institutions and political influences are further impacted by the role of the Catholic Church.

Traditionally Italian society has not been overly pluralistic, but on the contrary predominantly monolithic and lacking in religious diversity. The Muslim populations shared values and rules differ from the dominant Italian society. Among the concerns 
that are foremost by second generation Muslims, are their status in the public arena and their desire in maintaining connectivity with local Islamic institutions, and institutions outside of Italy. It is also culturally important for second generation Muslims to keep longstanding cultural ties with their parents' respective countries of origin.

\section{Factors influencing assimilation-the role of identity}

Additionally, with respect to the general tolerant attitudes that Italians have for immigration and in acceptance of religious minorities, existing factors that create barriers for integration remain prevalent. Some of the factors that generate conflict with respect to integration, are pointed out by Toronto (2008), “...the increasingly effective measures adopted by Muslims to promote their cause in the public arena, the role of second-generation Muslims in reconstructing Islamic identity for the Italian context... "[emphasis added], (Toronto, 2008, p. 61).

Relevant questions arise on successful integration, by addressing not only a relationship between Muslims and the majority of Italians, but also in framing this relationship between the state and Italian institutions, with Muslim communities and Islamic institutions. Encompassing these challenges for achieving greater assimilation include, the role of the State and the State's definition of concepts related to, needs, rights and belonging are entwined. As we seek to unravel further the dynamics associated with establishing citizenship and explore the notions sought by second generation Muslims in establishing equal footing, the State's role and institutions remain fundamentally important. 
The present day dynamics related to immigration and globalization complicate this process, generate forms of exclusion and hamper the process for assimilation further. Silvestri (2010) illustrates, "In short, Muslim communities are implicitly expected to adopt and adapt to the existing pattern of relations between the state and ethnic and religious communities in order to engage with the social and political context of where they live" [emphasis added] (p. 49). Consequently, this interaction, whether social or political, impacts the acceptance of new forms of institutionalization of Islam (other than mosques and Islamic schools), which increasingly have begun to appear throughout Europe, reluctantly, often through the direct intervention of European governments (Silvestri, 2010, p. 49).

Perhaps, an overarching reason impacting the dynamic for social transformation are the differences in lifestyles and the different ways in which social reforms are pursued and produced. Adding to these tensions and divisions remain the very notion generated by competing interests between second generation Muslims and the dominant culture, further complicated by traditional Italian society and its lack of cultural pluralism. As we look into these fundamental differences further, the need arises for establishing new ways for the Italian State to restructure the relationship between citizenship rights and the State's obligations to all of its citizens. Spena (2010) asserted that, "...In short, the people of the second generation have sought to synthesize community and identity references with the wider reality in which they live, work and begin new life projects" (p. 168). Articulating this point further, Spena notes that, 
"Young Muslims tend to find themselves torn between the need to be a part of Italian society and access all the possibilities that this offers them, and constant references to the mythical place of origin [emphasis added]" (Spena, 2010, p. 168).

Coexistence and inclusion are further complicated when we recognize that there are existing internal divisions and contradictions within Islam itself. The existing divisions within Islam, specifically for Italy, further exacerbate the process for establishing a unified structure, where State institutions and society adapts the necessary changes needed in addressing the structural changes needed for assimilation. My research and interviews conducted in Northern Italy validate the multi-ethnic composition of Italian Islam. Some of these divisions are attributed to, “...the conflicts between tradition and modernity, forms of democracy and the legitimacy of power, and conflicts between self-representation and other forms of representation" (Spena, 2010, $160)$.

Additionally, a second dimension impacting the internal divisions within the Islamic communities in Italy are the nature of the demographics. Unlike other European countries, the Muslim population in Italy is diverse, representative of several different countries of origin and scattered throughout the Italian peninsula. This representation from multiple Muslim countries, including for the second generation Muslims, impacts even greater the notion that there are internal divisions found within Islam. The Islamic community in Italy is a relatively recent phenomenon and remains somewhat divided. The importance that this community has acquired publicly has only surfaced in a post 
9/11 world. The Muslim presence and the public debate addressing the need for integration has emerged within the past decade as is a relatively new phenomenon for Italy and remains unchartered territory. Questions surrounding the definition of identity, generate conflict, where oftentimes second generation Muslims find themselves torn between, family ties, place of origin, the Muslim community and the host society in which they live in. "The overall question of migration, in fact, forces us to rethink the categories we use in comprehending our own identity" (Spena, 2010, 160).

In 2007, Frisina's ethnographic study shows:

Young Muslims tend to find themselves torn between the need to be a part of Italian society and access all the possibilities that this offers them, and constant references to the mythical place of origin. Because of their deeper ties to Italy and Europe, in comparison with their parents, they do not just claim the right to difference in Italian society, but also the right to equality (as cited in Spena, 2010, p. 168).

My literature suggests that, the presence of Islam in Italy is a relatively recent social and cultural phenomenon, which has been greatly impacted by the increasing number of Muslim migrants arriving and settling in Italy since the 1980's. The settlement for these new citizens in Italy has generated various tensions and is central to the notion of citizenship rights and achieving greater inclusion (Spena, 2010, p. 160). Given the diversity of the Muslim population, the complexity and multi-dimensional nature found in contemporary Islam, it would be unrealistic in providing an exhaustive narrative, encompassing all of dynamics related to assimilation in the $21^{\text {st }}$ century. To this end, I focused my study on the barriers for second generation Muslims, addressing factors that hamper the process for Muslims seeking to acquire equal footing. In her 
ethnography, Spena devotes a chapter in addressing "A breakdown of the Islamic presence in Italy" and explains the complexity of the dynamics unique to Italy and directly addresses my research question by stating some of the "obstacles which challenge $2^{\text {nd }}$ generation Muslims in achieving integration". Spena found that:

The multi-ethnic composition of Italian Islam, the stable presence of families, the question of women and members of the second generation, the issues of naturalization and conversion, the diverse geographical distribution and the types of settlement are all variables that have recently acquired greater importance and which frame any analysis of such phenomena (Spena, 2010, p. 161).

This study explores some of the realities prevalent that touch upon the implications for this process of social transformation, currently underway in Italy and found throughout Europe. The findings of this study have great implications for influencing social transformation and with providing insight on the broader challenges facing the second generation Muslims seeking greater status. The data collected for my study, suggest that the Muslim population in Italy is diverse and that multiple issues infringe upon achieving social equality and greater rights within a religious framework. These divisions are further heightened when we compare religious beliefs and lifestyles of one cultural grouping, with the notions of inclusion, citizenship and cultural differences present by the dominant Italian culture.

When we compare religious beliefs and lifestyles of Italian-Muslims, with that of mainstream Italian society, the cultural and religious disparities found become more evident. As stated in my hypotheses, this tumultuous relationship, between mainstream Italians and Italian-Muslims, is further amplified by the privileged position of the 
Catholic Church, and its failure in validating Islam in a broader sense. Additionally, Italian nationalism conveyed by political movements and ideology, primarily the "Northern Italian League" (Lega Nord), further exacerbates the notion of coexistence, by assuming an "anti-migrant, exclusion and anti-acceptance" stance for all Muslims. Spena (2010) further illustrates:

The focus of discussion is not just Italy's relations with migrant citizens and an understanding of their demands, but also the "constitutive relationship between, on the one hand, the beliefs, lifestyles, and claims of immigrants, and on the other, the notions of citizenship, rights inclusion and coexistence that frame the European-Italian perspective (p. 160).

My study sought to validate this process and establish the need to alleviate intolerant attitudes found in Italian society, based upon pre-established biases toward Muslims and shedding some light on the often misleading public image of Islam in Italy. Much of the negative stereotypes related to Islamophobia and xenophobia are predominantly influenced by negative stereotypes conveyed by the media. My hypothesis is based on this notion, "factors that impede the efforts of Muslims to achieve equal footing in the Italian religious landscape including the diversity and divisions found within the Muslim community itself". This process is further amplified by a general mistrust of Islam found in mainstream Italian society.

In a recent article published in Italy's "Yalla Italia", a magazine founded in 2007 focused on issues facing Muslim assimilation, Professor Sabahi addresses the need for designing and developing a structural process by the state, which would address existing complex issues from citizenship rights to coexistence. This structural 
framework would narrow the cultural divide, most notably by addressing lifestyle

differences, including dress for women. Sabahi (2009) illustrates:

Italy's immigrants are relative newcomers, compared with those elsewhere in Europe, and the country is still struggling with how to deal with its growing foreign population. After the Italian Senate passed a bill toughening immigration policies in February, "Famiglia Cristiana", an influential Roman Catholic magazine, accused Italy of plunging "into the abyss of racial laws", a series of anti-Semitic measures that were passed by the Fascist government in 1938. The lower house still has to approve the bill, which would be one of the strictest in Europe. "Italy hasn't chosen a specific model yet for how it wants to deal with Islam", said Farian Sabahi, a professor of history of Islamic countries at the University of Turin. "It hasn't been a priority of the government, and that is embarrassing, because it goes against what other European countries are trying to do" (as cited in Povoledo, 2009).

It is important to recognize to critical factors that influence greatly the future of Muslim assimilation within the Italian context. First, from a sociological perspective, when evaluating a potential model for future integration, Italy is a unique situation when compared to the rest of Europe. The second generation Muslim population found in Northern Italy represents specific challenges and demographics, when compared to Europe. When analyzing Muslim assimilation, typically references are made to Italy's distinctiveness by sociologists and scholars. Second, Italian Islam remains predominantly first generation, although the population of second generation Muslims is growing, younger, better educated and becoming more significant in promoting their cause. Spena (2010) highlights that “...the needs of the Muslim community are rarely met with a unified, structured response from the Italian state" (p. 166). 


\section{Findings and Limitations}

My research and interviews validate the need for designing a model of integration, this process should include greater emphasis for the second generation Muslim population, who in my view, represent the principle religious minority who are most likely in having a future role impacting the shaping of Italian society. The second generation will likely have a greater role in forming the future of Italian society and in restructuring the Italian religious landscape as they engage in ongoing debates on topics related to; national identity, human rights and the nature of civil society. There are several principle groups representing the Muslim community and involved in the negotiations with the Italian State and society, UCOII (Union of Islamic Organizations and Communities in Italy), the Islamic Cultural Centre of Italy (which is based at the mosque of Rome and is recognized as an institutional body), ADMI (Association of Muslim Women in Italy) and the GMI (Young Muslims in Italy) are the prominent four groups. Spena (2010) points out that; “The $\boldsymbol{A D M I}$ and the $\boldsymbol{G M I}$ are both recently formed organizations that make specific request regarding youth and gender issues" ( $\mathrm{p}$. 170). Due to an arrangement made by Professor Branca in Milan, I was fortunate to have participated in the GMI conference held in Umbria, Italy in December 2008, where I engaged in Muslim youth focus group discussions and gathered first hand data as to the overall concerns and issues resonating with second generation youth.

In my discussions with Muslim community leaders, Italian scholars and in my participation with Muslim youth focus groups, I have noted that an existing pattern 
emerges. From my discussions and interactions, it was clearly evident that a conflict of interests emanates and that a divide exists. This is due to the competing visions between second generation Muslims (as a minority grouping) and their vision for integration, whereas on the other hand, the view of the dominant non-Muslim population, including the Italian State.

As discussed in my methodology, my hypothesis emphasizes the negative stereotyping by Italian media and how this potentially impacts the trend of "Islamophobia". This relationship is further complicated by the negative attitudes of Islam portrayed by the media and by the harsh political realities, encompassing a broader political narrative broadcasted by the Northern Italian League (Lega Nord). Additionally, this process for generating dialogue is further exacerbated by the perceptions of Islamic fundamentalism and terrorism, generating a kind of 'phobia of Islam', leading to anti-Muslim sentiments and resulting in a problematic relationship between Muslims and the dominant non-Muslim culture. Spena (2010), in referencing a recent study conducted by Ambrosini and Molina, presents an interesting example suggesting social and cultural conflicts experienced by second generation Muslims:

An interesting study by Ambrosini and Molina (2004), which attempts to build a phenomenology of the second-generation migrants in Italy, outlines a number of discontinuities, such as the rejection of the subaltern integration accepted by their parents and the specific search for identity that fluctuates between two opposite desires: to be inside, and to be outside (as cited in Spena, 2010, p. 168). Although, parental and family clashes may culminate for the second generation Muslim, as we explore deeper the barriers influencing Muslim integration and attempt 
to resolve this conflict, my research suggests that a common thread emerges. I sought to examine the meaning of this emerging trend, by engaging further with my subjects. This shared pattern is further evidenced by the concerns that the participants had, in which the second generation youth seek more inclusion and an active role in dialogue with the host society. Obtaining this enhanced process for engagement, would prove useful in developing a future model of integration.

As we examine in greater depth, Ambrosini and Molina's (2004) study showed that, "the specific search for identity that fluctuates between two opposite desires". This notion of fluctuating identities, suggests that a broader conflict presents itself, where a second generation Muslim struggles with issues related to forming an identity within the Italian context, different from their first-generation parents and different from the non-Muslim dominant culture prevalent in Italy. Moreover, in 2004 Spena's study refers to this fluctuating clash in search for restructuring identity in this way, "These are seen to generate clashes at individual, family, social and cultural level, and ultimately to culminate in radical conflicts, both with the symbolic universe of the community of origin and with the host society" (Spena, 2010).

My research participants and interviewees were based on second generation Muslims and representing a younger age demographic, their ages ranged from 18-26. In categorizing my participants by country of origin and gender, my objective was to obtain diversity for my study. Of the five second generation interviewees, the countries represented were "Egypt" (3), "Jordan" (1) and "Syria" (1), three were females and two 
males. This allowed for a diverse representation of the second generation Muslim population found in Northern Italy and reflects the Muslim demographic population that is typical for the industrialized Lombard region. My research questionnaire was designed to gain a broader meaning of understanding, by presenting open ended questions related specifically to the role of Islam and my subjects' perceived identity. That said, my intent was to generate discussion by the interviewees and I sought to gauge the degree in which Islam played in impacting their lifestyle and in determining their notion of identity.

In designing my research, I wanted to investigate further the notion of, to what extent the meaning of 'Islam' may have in influencing second generation Muslims and "how do you perceive your identity?" Additionally, in a country like Italy, having yet to develop a medium for trying to resolve the issue of second generation integration, any future model would have to include the shared values of the younger second generation Muslims. My research questions related to religion and identity were specifically focused on building a broader phenomenology, by encouraging dialogue and attempting to gain a better understanding related to my participants' sense of belonging within the Italian context. Since for many Europeans Islam represents a sense of dominance, I found it imperative to present questions designed in measuring the role of 'Islam' in one's life, and in addressing ones perceived identity, as this data may ultimately impact developing future models for integration. The degree in which second generation Muslims perceive themselves from a religious context and seek in 
reconstructing their Islamic identity related to the Italian context, is important in noting, for this impacts directly attempting to charter any future effective measures for establishing continuity in assimilation.

The results of my research suggest that second generation Muslims are seeking more inclusion within Italian society and greater civic engagement with State institutions. A divide currently exists between the Muslim community and Italian society. My research questions sought to validate the need for seeking a greater understanding in determining the complex setting of my population and by addressing the social and cultural dynamics, useful in drafting a better relationship between ItalianMuslims and mainstream Italian society. This could be further illustrated from the responses to my questionnaire, for example; one female respondent of Egyptian descent answered in this way:

"Please describe the meaning of Islam for you? Islam is my religion and my life"

(1) “How do you perceive your identity?” "I'm a young Italian Muslim" Another female respondent of Syrian descent gave a more comprehensive answer, and responded in this way:

(1) "Please describe the meaning of Islam for you?" "Islam is the religion of intellectuals, for those who seek in reaching a deeper understanding for the 
meaning of existence. Islam teaches you the best way to live your life by providing the proper guidance for achieving happiness..."

(2) “How do you perceive your identity?” "I consider myself European, Italian (of Syrian descent) and a Muslim, realizing that we are now living in a multi-ethnic society..."

My questions varied, my overall purpose was to gain a broader understanding in determining the likelihood for integration. This data, not only coincides with the literature presented in this study, but may be useful in drafting a future model for assimilation.

Another male respondent of Egyptian descent answered the following questions:

(1) “As a Muslim, what is the greatest challenge that you've faced with adapting to Italian society?" "To overcome the stereotypes and prejudgments"

(2) “Has perceived religious identity affected your adaptation into Italian public life?" "No,

I live happily my life as a Muslim”.

Additionally, another female Jordanian descent responded in this way:

(1) “As a Muslim, what is the greatest challenge that you've faced with adapting to Italian Society?” “One must begin without having prejudgments". 


\section{(2) "Has perceived religious identity affected your adaptation into Italian}

public life?" "Yes".

My research confirms the viewpoints of many scholars presented in the literature, that Italy has not chosen a specific model yet for addressing existing structural problems related to Muslim engagement and representation within Italian society.

\section{Study limitations}

This study was limited due to time constraints involving the exhaustive coordination of interviews and due to budget constraints. When I began my research in December 2008, my initial intent was to have ten completed questionnaires, which would entail interviewing ten participants, even with the assistance of Professor Branca from the Catholic University (Universitá Cattolica) in Milan, who assisted me in contacting the interviewees, this later proved to be an unattainable goal for several reasons. Primarily, due to time constraints and cost effectiveness, as my research progressed in Milan, achieving ten questionnaires proved to be an un-reachable task. The coordination of my interviews was further complicated by the fact that I began my initial phase of my research in August-September of 2008; this coincided with the Muslim period of Ramadan. For the majority of Muslims, Ramadan is a period of religious reflection, it is a month long period where Muslims are required to fast from dawn until evening and participate in additional prayers. Many take frequent trips to the Mosques during the entire month of Ramadan and their availability for interviews and 
discussion is limited. I planned on having five completed questionnaires, unfortunately, one of my participants filled in the basic demographic data on the questionnaire, but elected not to answer the questions, therefore my research resulted in having four completed questionnaires.

The overall goal while conducting research was to remain objective, I sought to immerse myself from my subject's point of view and minimize my biases. My overall intent was to convey a position of neutrality while conducting my interviews and while engaging with my chosen participants. To this end, every effort was made to be objective from the design of the data collection instrument, with my participation in focus group discussions, to the interview process and analysis. I sought to engage and view my participants from a theoretical lens, although I acknowledge that my own background, as a second generation Italian resulted in my having biases and has the potential of shaping my interpretations. During my research in Italy, while conducting interviews and my participation in the GMI Conference I was obviously viewed as a "non-Muslim" and my presence may have felt somewhat intrusive to my subjects. Creswell (2003), in his chapter "Socially Constructed Knowledge Claims", found that:

Researchers recognize that their own background shapes their interpretation, and they "position themselves" in the research to acknowledge how their interpretation flows from their own personal, cultural, and historical experiences. The researcher's intent, then, is to make sense of (or interpret) the meaning others have about the world (pp. 8-9).

Although the intent and purpose of my research was carefully explained to my selected interviewees in extraordinary detail, who were initially contacted by Professor 
Branca, some of my subjects remained skeptical, they doubted my position and research. Surprisingly, some of the participants actually feared that I was really a clandestine journalist, seeking to write an article on a Muslim residing in Italy for a local media publication. 


\section{CONCLUSION}

Given the daunting social challenges facing second generation Muslims in Italy, there is a critical need to establish a framework for societal integration and for fully embracing the concept of religious diversity, within Italy, as is validated by the scholarly literature and my research. Although a concerted effort in Italian society has already begun for Muslim integration, developing a successful model for assimilation in the $21^{\text {st }}$ Century, will likely assume greater importance as the population demographics are changing and the Muslim community increasingly adapts their efforts in seeking equal status. In order for Italian society to begin an effective medium in tackling the many obstacles facing Muslim equality, conflicting points of view on issues impacting, religious identity, rights, status and citizenship will require new thinking by Italian institutions, the state and more tolerance by the general population. My research and study validate that there are many multi-layered obstacles affecting this process for establishing greater equality and rights sought by the Muslim community. Listing in greater detail all of these challenges would undoubtedly result in an exhaustive narrative, bearing this in mind, the objective of my study was to validate the need for integration by conducting my research on location, engage with my chosen population and seek to discover common themes and patterns that play a prominent role impacting $2^{\text {nd }}$ generation Muslim integration.

In summary, the fundamental research hypotheses for this study is, that there are existing structural challenges within Italian society that create barriers for second 
generation Muslims who are seeking greater status and are exploring ways in reconstructing an identity that is consistent with Islam, with being a Muslim and favorable to Italian society. It is important to understand that the context is also historical, as a deeply seated mistrust of Islam is prevalent today within Italian society dating back centuries and precedes the religious wars of the middle-ages. The challenges that Muslims face in achieving greater status are further exacerbated due to a confluence of events. Among these existing overarching challenges, according to my hypotheses, are: negative stereotyping by media coverage which induces Islamophobia; the racist and anti-immigration narrative/rhetoric conveyed by the Political far-right (Lega Nord); the privileged societal position held by the Catholic Church hierarchy; inadequate implementation of the concept of multiculturalism, especially as seen in the limitations on Italian-Muslim citizenship rights and finally, the very diversity and divisions found among the Muslim migrant population itself.

Additionally, this study sought to answer the following two questions:

- "Will the reframing of Islamic identities and their compliance to Islam conflict with the generally tolerant Italian society?"

- "Is the resurgence of Islam in Italy, the practice of Islamic faith and ideology, truly compatible with secularism, democracy and European values?"

Consequently, the findings show that among the many social and political challenges that Muslims encounter seeking to achieve greater status, the question of citizenship is central in defining this process. My analysis concludes that, in correlation 
with my stated hypotheses, barriers remain preventing greater inclusion for $2^{\text {nd }}$ generation Muslims in Italian society. The most important of these have been shown by my study to be the negative stereotyping of the media generating Islamophobia, and the biased anti-foreigner stance demonstrated by the Lega Nord — both contributing to the marginalization of the $2^{\text {nd }}$ generation Italian Muslim population. $2^{\text {nd }}$ Generation Italian Muslims remain disenfranchised from mainstream Italian society. `A new model is needed addressing greater flexibility for gaining citizenship. Additionally, new thinking is needed by the Italian State and institutions, aligned with the EU, inducing policies designed to overcome the current multiple challenges faced by $2^{\text {nd }}$ generation Muslims, which would lead to greater integration and acceptance.

In her recent study, Spena (2010) argues:

It is not just the model of integration that needs to be reconsidered, but also the notion of citizenship, which has become highly disrupted through the reevaluation of social and cultural identity.

Access to citizenship and the consequent recognition of the status of the citizen should not be treated as a strictly technical and legal matter, but as a political and cultural problem, insofar as it has come to frame not only the politics of inclusion of the migrant population, but also to serve as a measure of the quality of democracy in Italy and the state's relationship with identity, rights and governance (Spena, 2010, p. 177).

Much of this thesis is comprised of an analysis of the current Italian Muslim situation and including data collected as part of this research project, and informed by a review of the relevant secondary literature. It is on these bases that I have drawn my conclusions. 
Promoting greater dialogue between the Muslim community and Italian institutions would benefit improving the process in drafting any future model for achieving Muslim integration. Subsequently, through dialogue and engagement and by addressing the barriers, this would lead to further inclusion within Italian society. "Yalla Italia" a non-profit publication devoted to promoting community awareness, has taken a proactive stance by engaging with the Muslim community. The magazine's goal is to "encourage mutual understandings" between the two cultures. Magazine contributor Ouejdane Mejri (2009) remains optimistic:

Yalla Italia hopes "to show Italians a constructive reality they don't expect", said Ouejdane Mejri, 32, a magazine contributor who came from Tunisia to study in Italy and now teaches information technology at Milan Polytechnic. "Immigrants are not just people who washed ashore on a beach. We pay taxes participate in society, strive to integrate. "We are the future of Italy", she said, "and we want to be protagonists of that future" (as cited in Povoledo, 2009).

\section{Suggestions for Further Research}

Suggestions in further research should include examining closer the internal dynamics impacting second generation Muslim youth, who are often torn between Muslim community values, Islamic institutions, fluctuating identities and the cultural values imposed by the state. Establishing citizenship in Italy still remains an ambiguous process. This is due to the nature of existing Italian laws, second generation Muslim youth do not necessarily assume the citizenship of the host society, but that of their parents. More research is needed on defining the impact of citizenship on the integration of second generation Muslims. The Muslim youth find themselves torn between two worlds; the world defined by Islamic teachings and the nation state, opposed by 
European cultural values. Additionally, it is worth further researching the impact of the Roman Catholic Church, the depth of influence that the Church promulgates on the barriers impeding second generation Muslim youth and the assimilation process. If the Catholic Church were to assume greater responsibility, could a future model prove useful in charting a successful integration program? How would the Muslim community benefit, if the Vatican adapted a policy seeking more interaction and engagement in dialogue with the Islamic institutions in Italy? In a recent study presented by Spena, I found it interesting, but not surprising how the majority of Italians "(55.3 per cent of Italians interviewed)" found that integration of the Muslim population poses greater challenges, when compared to the integration of "other immigrant populations" (Spena, 2010).

I strongly encourage more research from the aspect of gender, through the many encounters and discussions with young Muslim women; they are the segment of the population that is experiencing the greatest challenges, related to culture and identity. This is partially due to cultural traditions and the nature of Islam, where women are faced with choices related to their dress. The headscarf (hijab) is nearly mandatory for women of Muslim faith, and this is not the case for Italian women of the host society. Especially for the younger generation, Italy is a country that places a prominent cultural value on dressing fashionably. I interviewed and engaged in discussions with many Muslim women, including while attending the GMI conference in Umbria, where the headscarf was mandatory. Although many choose to wear the headscarf voluntarily, this 
continues to be a controversial topic, drawing much political debate and grasping the attention of the media. Recently France banned the niqab, which is full veiling, but these types of interventions by the state have widespread implications for Muslim women throughout Europe, regardless of what type of headscarf they may choose to wear. A more in depth analysis and further research on the barriers for Muslim women, the challenges they face related to integration, at the social and cultural level is worthy of further exploration.

Finally, after completing my interviews, research and engaging in the many discussions, not only with my research population, but also including Imams' who are representative of the Muslim community. I felt that I have gathered an exhaustive amount of data which goes beyond the scope of this thesis and maybe applied in the future for pursuing a doctoral dissertation. 


\section{References}

Allen, C. (2004). Endemically European or a European epidemic? Islamophobia in a post 9/11 Europe. In R. Geaves, T. Gabriel, Y. Haddad \& J. Idleman Smith (Eds.), Islam \& the West post 9/11(130-145). Burlington, VT: Ashgate Publishing Limited.

Allievi, S. (2003). Sociology of a newcomer: Muslim migration to Italy - religious visibility, cultural and political reactions. Immigrants \& Minorities, 22, 141-154. Doi: $10.1080 / 0261928042000244790$

Allievi, S. (2009). Conflicts over mosques in Europe: policy issues and trends. Retrieved from Catholic university of Louvain website: http://www.uclouvain.be/cps/ucl/doc/epl-orta/documents/Religion mosques.pdf

AlSayyad, N., \& Castells, M. (2002). Muslim Europe or Euro-Islam: politics, culture, and citizenship in the age of globalization. New York, N.Y.: Lexington Books.

Anastasiou, H. (2008). Encountering nationalism: the contribution of peace studies and conflict resolution. In D. Sandole, S. Byrne, I. Starosta-Sandole, \& J. Senehi, (Eds.), Handbook of conflict analysis and resolution (pp. 82-91). Oxford, England: Routledge.

Avruch, K. (1998). Part 1: Culture. In Culture and conflict resolution, (pp. 5-21). Washington D.C.: U.S. Institute of Peace Press.

Avruch, K. (1998). Part III: Frames for culture and conflict resolution. In Culture and conflict resolution, (pp. 57-72). Washington D.C.: U.S. Institute of Peace Press.

Erdenir, B. (2010). Islamophobia qua racial discrimination: Muslimophobia. In Triandafyllidou, A. (Ed.), Muslims in 21st Century Europe: Structural and cultural perspectives (pp. 27-44). New York: Routledge

Esposito, J. (2005). Islam the straight path. New York, N.Y.: Oxford University Press.

Gabriel, T., Geaves, R., Haddad, Y., \& Smith, J. (Eds.). (2004). Islam \& The West, Post 9/11. Burlington, VT: Ashgate Publishing Co.

Hellyer, H. (2006). Muslims and Multiculturalism in the European Union. Journal of Muslim Minority Affairs, 26, 3, 329-351. doi: 10.1080/13602000601141315 
Hirsi, Ali (2009, December 5). Swiss ban on minarets was a vote for tolerance and inclusion. The Christian Science Monitor. Retrieved from http://www.csmonitor.com

Huntington, S. (1996). The clash of civilizations and the remaking of world order. New York, N.Y: Simon \& Schuster paperbacks.

La dichiarazione finale del primo seminario del forum cattolico-musulmano. (2008, November 8). L'Osservatore Romano. Retrieved from http: www.vatican.va/news_services/or/home ita.html

Lewis, B. (1993). Islam and the West. New York, N.Y: Oxford University Press.

Lewis, B. (2001). The Muslim discovery of Europe. New York, N.Y: W.W. Norton \& Company.

Pandith, F. (2009, January 28). Re: Speech, Muslim engagement in the $21^{\text {st }}$ century (Facebook posting). Retrieved from http://fletcher.tufts.edu/news/2010/02/features/pandith.shtml

Povoledo, E. (2009, April 5). Italian magazine tries to narrow gap with Muslims. The New York Times. Retrieved from http://www.nytimes.com

Rath, J., Penninx, R., Groenendijk, K., \& Meyer, A. (2001). Western Europe and its Islam. Boston, MA: Koninklijke Brill NV.

Roy, O. (2004). Globalized Islam: the search for a new Ummah. New York, N.Y: Columbia University Press.

Silvestri, S. (2010). Public policies towards Muslims and the institutionalization of 'moderate Islam' in Europe: Some critical reflections. In Triandafyllidou, A. (Ed.), Muslims in $21^{\text {st }}$ Century Europe: Structural and cultural perspectives (pp. 45-58). New York: Routledge

Singer, M. (1998). The role of culture and perception in communication. In G. weaver (Eds.), Culture communication and conflict (pp. 28-53). Needham Heights, MA: Simon and Schuster.

Spena, M. (2010). Muslims in Italy: Models of integration and new citizenship. In Triandafyllidou, A. (Ed.), Muslims in $21^{\text {st }}$ Century Europe: Structural and cultural perspectives (pp. 160-180). New York: Routledge 
Ting-Toomey, S. \& Chung, L. (2005). What are the essential cultural value patterns? In S. Ting-Toomey and L. Chung, (Eds.), Understanding intercultural communication (pp.53-82). Los Angeles, CA: Roxbury Publishing

Toronto, J. (2008). Islam Italiano: prospects for integration of Muslims in Italy's religious landscape. Journal of Muslim Minority Affairs, 28, 61-82. 


\title{
Appendix A
}

Research Questionnaire

\author{
Muslim Migration in Italy Project \\ International Conflict Resolution \\ Principle researcher; Joseph A. Migliore \\ Conflict Resolution Graduate Program (CR) \\ Portland State University, Oregon - U.S.A. 97207-8441 \\ Phone Numbers: Italy 39-(347) - 5587129 or U.S. Mobile (503) 778-0790 \\ E-mail: Josephflashoverride@gmail.com
}

\section{Questionnaire}

You are invited to participate in a research study conducted by Joseph A. Migliore from Portland State University; Joseph is a graduate student with the Conflict Resolution Department.

Part I - Personal Data

Age: $\square 18-21 \quad \square 22-25 \quad \square 26-29$

Sex: $\square$ M $\square$ F 
Social Status: $\quad$ Student $\square \quad$ Employed $\square \quad$ Unemployed $\square$

Country of Birth:

Father's country of Birth:

Mother's country of Birth:

If you hold citizenship other than Italian; I have been residing in Italy since (please indicate the year):

Part II - What is the significance of Islam for you?

(Please note, that you may select more than one response, in order of importance to you)

$|1| 2|3| 4 \mid>$ Islam is faith and religion, homeland and nationality, religion and State, spiritual adoration and taking action, Books and sword

$|1| 2|3| 4 \mid>$ My wishes are that my servants glorify me when they think of me; by remembering me they remain loyal, by remembering me they display their obedience, by carrying out my wishes they display their thankfulness, and they display their love for me by every light that I shed upon them

| $1|2| 3|4|>$ Islam is the act of knowing how to live your daily lives with great spirituality and serving for the good of the future. Islam signifies humility, simplicity and not having power, superiority or displaying arrogance 
$|1| 2|3| 4 \mid>$ Islam may not be reduced to a single political cause or be representative of cohesive nationality. Its shahada (sahăda), a deposition of faith in which we express by speaking, felt in the heart and applied by total commitment of the person

\section{Part III -}

1) How do you perceive your identity?

Example: European --- Muslim --- Italian

2) How has Islam impacted your public life, while living in Italy? 


\title{
Appendix B
}

\author{
Human Subjects Application
}

July 5,2008

\author{
Muslim Migration in Italy Project \\ International Conflict Resolution \\ Conflict Resolution Graduate Program-CR \\ Portland State University (PSU) \\ PO Box 751
}

Portland, OR 97207-0751

Phone: (503) 778-0790

Fax: (503) 725-9174

\section{Project Title and Prospectus}

Muslim Young Adults in Northern Italy Project

The religious presence of Islam in Europe has seemingly become a controversial public debate recently. There are several reasons why the controversy and debate over Islam vs. European values has re-emerged on the European political and cultural landscape. Perhaps in this era of globalization, this increasingly popular phenomenon of Islam and Muslim integration for Europe has drawn so much public attention recently may be due to the very nature of Islam itself and the religious visibility that Islam poses publicly. Having this visibility challenging European values, identity, 
further creating cultural and social obstacles, thus, leading to an atmosphere of debate and generated conflict between Europeans and Muslims seeking to integrate and reintroduce their Islamic identities. Consequently, it is not surprising that Islam within the past fifteen years has become the second largest religion in Europe, validating a need for cultural integration and requiring social transformation for Europe and Italian society.

In contrast to most of Western Europe, Islam has established a growing presence in Italy only within the past ten to fifteen years, Muslim integration within Italian society is a relatively new phenomenon. Unprecedented in its magnitude and frequency, this increasingly migration from Islamic countries has brought about a new dimension for Italian society, particularly within the public sphere. Recent Muslim migrants to Italy, whether first or second generations have intertwined into a cultural mix of racial, ethnic and religious groupings, thus, recent literature and scholars acknowledge that this new dimension of migration has generated conflict in the public domain. Consequently, inducing new debates about multiculturalism, national identity, human rights and most importantly to what extent do we allow Muslim integration into Italian society and the public sphere? In this process, Muslims in Italy are contrary to being treated as outsiders, but many also face barriers to assimilation within Italian society and seek the same status as Europeans.

My research will focus on the dynamics of Muslim immigration and integration into Northern Italian society, addressing the barriers to assimilation in Italy -- a country which holds traditional European values -- and focusing on the issues surrounding this public debate in Italy. The recent influx of new Muslim populations in Italy has developed into two phenomena; recently migrating Muslim youth are seeking to establish their own place within Italian society, seemingly reconstructing their own Islamic identities, consequently causing Europeans to rethink their own identities as European Union (EU) member citizens. Italy although secular and tolerant towards religious minorities, seemingly holds a mistrust of Islam within Italian society; this is partially true due to two primary reasons. Italy's extensive media coverage of Islam and Muslim communities tends to be bias and inaccurate, secondly due to the political and religious influences of the Catholic Church exhibiting its influence toward Islam and other religious minorities.

My research will seek to explore the social, cultural and political dynamics presented by the religious visibility and growing presence of Islam, addressing the public debate generated by Muslim immigration/integration within Italian society. Research indicates that contemporary trends in immigration, suggesting demographic 
changes for Muslims migrating to Italy from Northern Africa are difficult to obtain or at best sketchy. My research will address the question of how many of the Muslim immigrants actually consider themselves Muslim, whether due to cultural identity, or acknowledging religious observance, as a recent scholar has noted, this phenomenon remains unclear and virtually unexplored, due to the influx of migration to Italy that has occurred recently. My literature indicates that approximately 33\% of immigrants to Italy are from Muslim countries, according to the ISMU (Iniziative e Studi Sulla Multietnicita'), the largest percentage of recent migrants are from Morocco (based on my ISMU conference attendance in Milan, Italy - April 2008). The significance of this research will seek to address the dynamics of how increasingly Muslim populations in Italy will assimilate into Italian society. I will examine the process of newly arriving Muslims face in their efforts to establish their own cultural integration into Italy. Moreover, I will explore the value of Islamic identity and its relation and acceptance by Italian society.

What will the future impact for Europe hold with the resurgence of Islam on the European Continent, how will this impact Italy with assimilation of its increasing Muslim population? Theoretically speaking, within Islam there is no separation between religion and state, Islamic law replaces secular governments. Many Muslims that have migrated to Italy, tend to embrace democratic values while seeking to embrace their Islamic identities, they rely on community leaders and Islamic family law to guide their daily lives. Will the reframing of Islamic identities and their adherence to Islamic principles conflict with the generally tolerant Italian society? Is the resurgence of Islam in Europe, the practice of Islamic faith and ideology, truly compatible with secularism, democracy and with European values? My topic presents a complex phenomenon; I seek to address if the future of Muslim assimilation into Italian society will be compatible with secularism and with Italian values. By observation and while conducting my interviews of recent Muslim youths in Italy, I hope to formulate my theory on Islam, Muslim migration and integration. My research will be based on interviews of recent Italian Muslims and by gathering data on what Muslims themselves think and view their assimilation process into Italian society.

\section{Exemption Claim for Waiver of Review}

Expedited review requested. 


\section{Subject Recruitment}

My research will be qualitative, based on theoretical sampling. I plan on conducting a Case Study utilizing three principle methods for my data collection; (1) observation while on site (Milan) (2) Interviews and (3) Document review. I will structure my individual interviews by presenting the interviewees with a "pre-drafted" questionnaire. I recently completed my U.S. Department of State internship in Milan, Italy. During my internship in Milan (April 2008), I attended a major forum hosted by the Italian foundation ISMU (Iniziative e Studi Multietnicitả) on immigration highlighting ideas and programs that where needed to better facilitate integration for recent migrants to Italy. During the ISMU forum, which identified current immigration trends, it was noted that the number one immigrant population for the Lombard region where Moroccans, superseding previous demographics. The ISMU forum was representative of Italian academia, Muslim scholars, NGO's and government representatives that where seeking ways to improve the assimilation of Muslim migrants into Italian society. The participants for my study (interviewees) will be established from prior contacts that I have made while on my internship in Milan. I plan on selecting my interviewees randomly, limiting the number of interviewees from 10 to 13 . The principle translator (Prof. Paolo Branca) and Mr. Joseph A. Migliore will be responsible for recruiting all participants. My participants will be selected through three primary contacts in Italian academia that are well established within the Muslim community in Northern Italy: Prof. Paolo Branca, Senior Researcher \& assist. Professor of Arabic \& Islamic studies, from the Catholic University - Milan; Prof. Vincenzo Cesareo, General Secretary of ISMU, \& Professor of Sociology from the Catholic University - Milan; Prof. Stefano Allievi, Professor of Sociology leading Italian scholar on Multiculturalism and Muslim Migration, University of Padua, Italy.

My interview population will be voluntary and representative of recently migrated Muslim young adults, (18--28 years of age), from Morocco, Tunisia, Senegal, Egypt, Somalia, Algeria, Nigeria, Bosnia and Turkey. In order to achieve adequate representation, I plan on interviewing $1^{\text {st }}$ and $2^{\text {nd }}$ generation migrants to Italy, who consider themselves Muslims and are from predominantly Islamic countries; I will select interviewees who are mostly representative of recent migrants; young adults who 
have migrated for economic reasons, since this represents the majority of the Italian migrant population. I plan on also interviewing one or two Muslim university students, for this data may prove to illustrate an easier process with adaptation due to acquired language skills and education/class variation.

My interviewees will include adequate representation of gender; I plan on interviewing at least 2 to 3 Muslim women, although proportionately the male participants will be greater. I plan on including members of the Muslim community indicated, as potential participants for my interviews. My research and interviews will not be limited to recent migrants to Italy; I will also interview 2 or 3 Italian scholars on Islam and Muslim migration and one Islamic community leader from Milan. I would also attempt to schedule an interview with the local imam at the principle mosque on Viale Jenner in Milan. My interviews will be conducted in Milan and Padua, either at the University of Milan or Padua, or at a pre-established Muslim community center and/or Mosque in Milan, Italy. Participants will be asked a variety of questions related to their background, religious identity and their experience with assimilation into Italian society. The focus of my research will attempt to explore the social, political and religious conflicts that mass immigration of Muslims has generated in Italian life. My research will highlight the internal and external challenges that Muslim migrants face with adaptation and integration into the Italian society. My research will seek to shed some light on the acceptability of Islam and religious minorities and whether Muslims, who have recently migrated, will have an opportunity to assimilate into Italian society successfully.

\section{Informed Consent}

Consent will be obtained by the Principal Researcher (Joseph A. Migliore), a preapproved consent form (Please view my Appendix), will be dispersed to each participant prior to conducting my interview. The participants will be adult subjects, conforming to the legal statues of Italian law (18 years of age and older). My research interview and participation with my questionnaire will be strictly on a voluntary basis. The interviewees will be presented with my consent form (see appendices), before any information is asked of them, they will be asked to read over and sign the consent form that can be found in the Appendices of this application. Consent and approval will be obtained before research participants have their answers and related comments recorded 
by the Principle Researcher. Interviews will be one on one, conducted in a safe and comfortable environment. I may have Professor Paolo Branca, (senior researcher and Assistant Professor of Arabic and Islamic Studies) - from the Catholic University of Milan, present for my interviews, this will be optional. If required, a translated written consent document in a language understandable to the participant (Italian or Arabic) will be provided prior to any interview. This will be an accurate translation of the full informed consent included in my application (Appendix for English version).

\section{First Person Scenario}

I received a phone call yesterday from Prof. Paolo Branca, from the Islamic Studies department at the Catholic University of Milan; Prof. Branca mentioned to me that a Portland State University Graduate student in the Conflict Resolution program will be conducting his thesis research in Milan on Muslim integration into Italian society. Prof. Branca had asked me if I were interested in participating in graduate student Joseph A. Migliore's research on the Italian Muslim integration project. I was told that Joseph attended the ISMU forum in Milan on multiethnicity and immigrant integration into Italian society last spring. During the ISMU form on multiehnicity and immigration, Joseph met many Italian scholars on the topic of multiculturalism, sociology and Muslim integration within Italian society. Prof. Vicenzo Cesareo, my former sociology professor from the Catholic University in Milan, represented the ISMU at the forum and is a leading scholar on the topic of migrant integration; he had also mentioned to me that Joseph would be conducting his thesis research on this topic in Milan, beginning in late August 2008. I attended the same forum on migrant integration at the Milan convention center last April as well! As a recent Muslim living in Italy, it has been a difficult process with my adjustment in Italy, I welcome this opportunity with engaging in this research project, having the opportunity to share the aftermath of my experiences and with sharing what my religion means to me culturally, this process will give me a sense of belonging within the community.

I am aware of the social and cultural hardships that I have had to face adjusting to Italian society, much of the social infrastructure and organizations in Milan have not been very supportive to my needs with adapting to my new community in Italy. As a recently migrated Muslim and as a women I felt that I would have a lot to discuss during the interview process representing Joseph's research topic, Prof. Branca had 
mentioned to me that I would be required to sign a consent form before participating in the research and that there would be a questionnaire for me to answer. I was delighted to have this opportunity to participate in this thesis research that directly affects my own personal experiences as a Muslim, recently having to adapt to Italian society. As a research participant, I would like to share with Joseph what I knew from my personal experiences and how that has impacted my life and my interactions in Milan as a Muslim woman. I was given the consent form to look over and Joseph mentioned that he would be happy to answer any questions or concerns that I may have. I was told that the interview and questionnaire process would take approximately an hour, and that all the information that I would share would remain confidential. I am looking forward to meeting Joseph, and with participating in this study and with sharing my experiences.

\section{Potential Risks and Safeguards}

The potential risk for participants in this research is a stimulation of emotions related to sharing their individual experiences within the context of adjusting to Italian society as recent migrants from a Muslim country to Italy. This risk may be perceived by causing emotional stress due to the participant sharing information outside the bounds of their culture, naturally, any concerns or discomfort during the time of interview will be appropriately dealt with, my primary goal will be to create a pleasant and relaxing environment where I will be conducting the interviews. I will be conducting interviews within the setting of a safe environment, to be established. While coordinating with Prof. Cesareo and Prof. Branca, I plan on conducting the interviews within a designated comfortable office setting that will allow privacy, either at the Catholic University or at the ISMU, the Italian organization dedicated to the research and study on immigration and multiethnic integration. Participants will be free to withdraw from the interview or questionnaire and from the study at their own discretion. Participants will be given the safeguard of absolute confidentiality. The confidentiality details are included in detail in Section VIII. Additionally, the transport of all data will be secured on an external hard drive with password protection. I believe that the security of this hard drive will be sufficient, consequently, for true safeguarding purposes, all original data and the data file drive being used to store this information will be kept in a secure backpack that only I will possess and store. 


\section{Potential Benefits}

The social and cultural challenges presented by the insertion of Islam within Italy's spiritual geography, will be illustrated by the voices and perspectives shared by individual experiences gathered by my research. Evidence suggests that integration of Muslim migrants within Italian society is underway, and my research will provide a greater understanding of immigrant experiences from a diverse cultural perspective. There are many challenges that recent migrants from Muslim countries face with the process of adapting to Italian society, some are related to gender, religious identity and this process of integration is further complicated by attitudes of mistrust of Islam in Italian society. My research and data collection, will help to shed some light on the experiences of recent immigrants to Italy, how they have had to adapt as religious minorities, my research will illustrate some of the social and cultural challenges that they face as Muslims, these personal experiences that I hope to document will help scholars and future planners formulate the successful integration process for religious minorities. A greater understanding of framing the challenges faced my Muslims adapting to Italian society, will lead to regional governments and organizations supportive of multiculturalism, with adapting effective measures to accommodate and promote the successful integration of Muslims and easing the mistrust of Islam which has been amplified by biased media coverage. My research goal is to promote a greater understanding of Islam, Muslims residing in Italy and with promoting successful integration into Italian society.

\section{Records and Distribution}

\section{Confidentiality}

All participants will be provided confidentiality regarding their contributions to the research, their identities will remain anonymous. Their names will be replaced with a number, I will have a numbering system that will be associated with each participant, this documentation will be in my possession and properly safeguarded for the duration of my research, and for the period thereafter. The main numbering list for the duration of the research period will be kept in the personal files of the principle investigator. This listing will be kept separately from all the documents concerning the research. The data 
will be stored with my personal files, while I am conducting my research in Italy, and will remain stored with my personal files for the duration of my study and thesis upon returning to Portland State University (approximately for one year). The only other place that a confidential name will appear will be on the consent forms that they have signed prior to any participation with the research study, the consent forms will remain safeguarded in my possession with my personal files. The consent forms will be kept separate from the study documents, to ensure its safety and protection. At the end of the research, the numbering list and consent forms of individuals who choose to keep their information confidential will be placed in private storage and destroyed three years after the research's completion. I will be the only person who will have access to the research interview data, questionnaires, consent forms and the recorded materials. I will record my subjects' by audio taping during their participation with the questionnaire, the option of recording my subjects during the questionnaire completion will be addressed prior to subject participation, I will explicitly request the participants consent for recording their responses to the questionnaire on the consent form (See my appendix).

\section{Appendices}

Questionnaire

Consent Form 


\title{
Appendix C
}

\author{
Human Subjects Consent Form
}

Muslim Migration in Italy Project

International Conflict Resolution

Conflict Resolution Graduate Program-CR

Portland State University (PSU)

PO Box 751

Portland, OR 97207-0751

Phone: (503) 778-0790

Fax: (503) 725-9174

\section{Consent Form}

You are invited to participate in a research study conducted by Joseph A. Migliore from Portland State University; Joseph is a graduate student with the Conflict Resolution Department.

Objective: The researcher hopes to learn the context of the hardships being endured by recent Muslims adapting and establishing themselves in Italian society. From my research interviews and with your participation in a brief questionnaire, I seek to expose many of the cultural and social challenges experienced by recent migrants to Italy from Muslim countries. My research will focus on the dynamics associated with Muslim immigration, social adaptation and integration into northern Italian society. My 
research goal is to unravel some of the hardships and conflicts associated with cultural barriers that may infringe upon Muslim migrants adaptation and general integration into Italian society. My study is being conducted in partial as a fulfillment of the requirements for a master's degree; I have chosen this topic and research as part of my master's degree thesis academic requirement. My thesis research will be under the direct supervision of Dr. Harry Anastasiou, Professor of International Peace and Conflict Studies, who is my principle graduate program advisor. You were selected as a possible participant in this study because you have been identified as a recent Muslim migrant living in Milan.

Procedure: If you decide to participate, you will be asked a variety of questions related to your history, your cultural and communal experiences, and related to your experiences as a recent migrant in Milan. Your participating with this research project will entail your participation in an individual interview and by responding to the questions presented in the questionnaire. Graduate student, Joseph A. Migliore from Portland State University will be conducting your interview and facilitating the questionnaire during the interview. The questionnaire and interview process will take approx. 30 minutes. My questionnaire has five general questions related to Islam, cultural differences, language and poses question related to adaptation within Italian public life. While participating with this research study, you will be asked to be audio taped by the researcher during the questionnaire answering session and your responses to the questionnaire and the audio recorded material will be kept strictly confidential and will by used only for academic research purposes. You may decline to be audiotaped, and still maintain the option to participate in the interview (Please indicate at the bottom of the consent form if you choose to decline to be audio-taped). Please remain confident that the interview session and research questionnaire that you will be asked to respond to will remain confidential and safeguarded by the principle researcher. You may not receive any direct or financial benefit from taking part in this study, but the study may help to increase knowledge, promote cultural awareness and which may help facilitate an easier immigration and cultural adaptation process to others seeking to live in Milan in the future.

Confidentiality: Confidentiality will be maintained throughout the research and interview and remains a critical part of the research process. It encourages candid responses, open discussion and a full exploration of issues that may be relevant. Any 
information that is obtained in connection with this study and that can be linked to you or identify you will be kept confidential. Your identity and personal information will be only known and safeguarded by the principle investigator, Joseph A. Migliore and known by my academic assistant advisor in Milan; Professor Paolo Branca, Senior researcher and Assistant Professor in Arabic and Islamic Studies, who is currently with the Catholic University in Milan. Prof. Branca, will have knowledge of the subjects who will be randomly chosen for my research interviews, due to his academic assistance with my graduate thesis and research process. Prof. Branca lives in Milan, he is a scholar on my topic and a well know person within the Islamic and academic communities, Prof. Branca will assist me with randomly selecting participants for my interviews and research. The research information that you will provide, and your identity will be coded by a numbering system that I will facilitate. In a effort to protect your confidentiality and privacy only the principle researcher (Joseph A. Migliore), will have access to the numbering system and will maintain and safe guard your responses and the audio recordings in my own personal backpack. My research data, information gathered and my personal backpack will always be either in my possession, on locked and safeguarded in my Hotel safe while in Milan. All communication made in, or in connection with the interview and questionnaire process is confidential and will not be released for any purpose not related to my research study described above.

Potential Risks: The potential risk to participants may be perceived emotional stress due to sharing information outside the bounds of their culture. Any discomfort during the time of interview will be addressed by offering a pleasant and relaxing environment.

Benefits: Your participation is voluntary. You do not have to take part in this study, and it will not affect your employment, academic program, course work or your relationship with your professors at the Catholic University in Milan (Prof. Paolo Branca, Islamic Studies, Catholic University Milan -- Italy, or with (Joseph A. Migliore, Graduate Student at Portland State University, Conflict Resolution Department). You may also withdraw from this study at any time without affecting your relationship within your community, or with the ISMU (Iniziative e Studi Sulla Multietnicitả) or with your academic university affiliation, or with your status of employment. Although you will not receive any salary or direct benefit from taking part in this project, I appreciate your time and contributions, as this research project will gather valued information and increase knowledge which may help others in the future with the immigration process 
and with adapting to Italian society in the future. Your participation with this research will help promote cultural awareness, improve knowledge on religious aspects associated with Islam and possibly improve accommodations for future Muslims who chose to immigrate to Italy. If you do not take part in this research or interview, it will not affect your status in Italy, or affect your employment/academic program at the university. However, if you choose to participated, you are kindly asked to remain committed to the entire research process as required.

If you have concerns or problems about your participation in this study or your rights as a research subject, please contact:

Human Subjects Research Review Committee, Office of Research and Sponsored Projects, 600 Unitus Bldg., Portland State University, Portland Oregon - U.S.A. (503) 725-4288 / U.S. 1-877-480-4400.

If you have questions about the study itself, contact:

Principle researcher; Joseph A. Migliore at P.O. Box 8441, Portland Oregon - U.S.A. 97207-8441, my phone numbers are: Italy 39-(347) - 5587129 or U.S. Mobile (503) 778-0790. E-mail: Josephflashoverride@gmail.com

Or

Research Advisor in Milan, Italy; Professor Paolo Branca, Senior Researcher and Assistant Professor of Arabic and Islamic Studies, Universitả Cattolica, Milan Italy. Phone Number: (Italy) 39-02-70631910 or Fax. Number: 39-02-72343712. E-mail: Paolo.branca@unicatt.it 
Your signature below indicates that you have read and understand the above information and agree to take part in this project and process.

Please understand that you may withdraw your consent at any time without penalty. The research facilitator will provide you with a copy of this form for your own records.

\section{Audio-taped participation:}

Yes, I agree to be audio-taped

No, I do not wish to be audio-taped

$-$

Your Signature

Date

Interviewer Signature

Date 